\title{
IMPLEMENTAÇÃO DE UM SISTEMA DE QUALIDADE PARA LABORATÓRIO DE ANÁLISE SENSORIAL BASEADO NO SISTEMA DE BOAS PRÁTICAS
}

ANGELA DE FATIMA KANESAKI CORRÊIA

Dissertação apresentada à Escola Superior de Agricultura "Luiz de Queiroz", Universidade de São Paulo, para obtenção do título de Mestre em Ciências, Área de Concentração: Ciência e Tecnologia de Alimentos.

PIRACICABA

Estado de São Paulo - Brasil

Junho - 2005 


\title{
IMPLEMENTAÇÃO DE UM SISTEMA DE QUALIDADE PARA LABORATÓRIO DE ANÁLISE SENSORIAL BASEADO NO SISTEMA DE BOAS PRÁTICAS
}

\section{ANGELA DE FATIMA KANESAKI CORRÊIA}

Engenheira de Alimentos

Orientadora: Profa. Dra. MARTA HELENA FILLET SPOTO

\begin{abstract}
Dissertação apresentada à Escola Superior de Agricultura "Luiz de Queiroz", Universidade de São Paulo, para obtenção do título de Mestre em Ciências, Área de Concentração: Ciência e Tecnologia de Alimentos.
\end{abstract}

PIRACICABA

Estado de São Paulo - Brasil

Junho - 2005 
Dados Internacionais de Catalogação na Publicação (CIP) DIVISÃO DE BIBLIOTECA E DOCUMENTAÇÃO - ESALQ/USP

Corrêia, Angela de Fátima Kanesaki

Implementação de uma sistema de qualidade para laboratório de análise sensoria baseado no sistema de boas práticas / Angela de Fátima Kanesaki Corrêia. - Piracicaba, 2005.

95 p. : il.

Dissertação (mestrado) - - Escola Superior de Agricultura Luiz de Queiroz, 2005. Bibliografia.

1. Administração da qualidade 2. Alimentos - Controle da qualidade 3. Indústria de alimentos 4. Laboratório - Análise sensorial 5. Manipulação de alimentos

6. Monitoramento 7. Normalização 8. Segurança alimentar 9. Tecnologia de alimentos I. Título

CDD 664

"Permitida a cópia total ou parcial deste documento, desde que citada a fonte - 0 autor" 


\section{DEDICATÓRIA}

Dedico este trabalho à Ana Claudia Kanesaki Correia minha filha e Antônio Nelson Correia Filho meu esposo, pelo apoio e compreensão. 


\section{AGRADECIMENTOS}

Muitos foram os que proporcionaram o desenvolvimento deste trabalho, pois não há nada que possa ser realizado de forma isolada. A todos os colaboradores presto minha homenagem e meus sinceros agradecimentos.

A Deus pelo dom da vida, pela oportunidade e força concedida para a finalização de mais este desafio

A nossa Senhora Aparecida, suprema luz e fé que sempre preciso.

A orientadora, profa. dra. Marta Helena Fillet Spoto, pela orientação e compreensão, pela força nas horas mais difíceis e pela liberdade que sempre me concedeu.

Ao prof. Antônio Nelson Correia Filho, pela contribuição com subsídios que enriqueceram os estudos.

Ao amigo, prof. Izael Gressoni Junior, pelo brilhante auxílio técnico.

Aos amigos e colaboradores da indústria de alimentos que concederam o desenvolvimento e aplicação do trabalho.

Aos professores membros da banca examinadora pelas sugestões e opiniões.

As minhas irmãs, que mesmo a distância, transmitiram confiança e incentivo a minha pessoa.

A amiga Luciana Marchese pelas opiniões e idéias concedidas.

A Beatriz Helena Giongo, pela revisão da dissertação.

Aos colaboradores do departamento de Agroindústria Alimentos e Nutrição, pela dedicação e carinho.

Ao SENAI - Serviço Nacional de Aprendizagem Industrial.

A todos que direta ou indiretamente contribuíram para a realização deste trabalho. 


\section{SUMÁRIO}

Página

LISTA DE FIGURAS........................................................................ ix

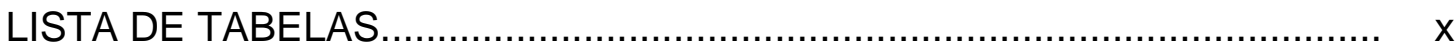

LISTA DE ABREVIATURAS E SÍMBOLOS........................................... xi

RESUMO .....................................................................................

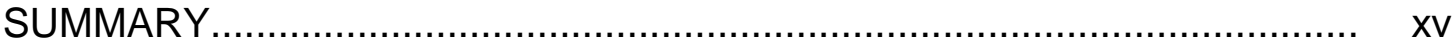

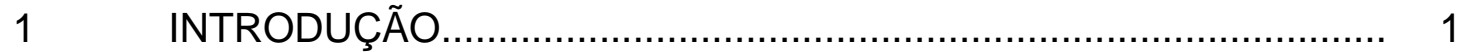

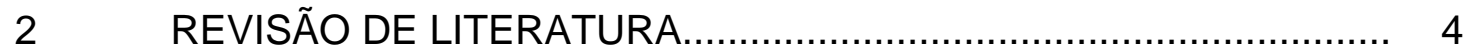

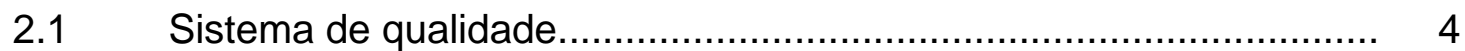

$2.2 \quad$ Sistema de qualidade em serviço.................................................. 7

$2.3 \quad$ Boas práticas de laboratório.................................................... 8

2.4 Boas práticas de fabricação...................................................... 12

2.4.1 Procedimento padrão de higiene operacional............................... 12

2.4.2 Controle integrado de pragas................................................... 13

$2.5 \quad$ Monitoramento e avaliação......................................................... 15

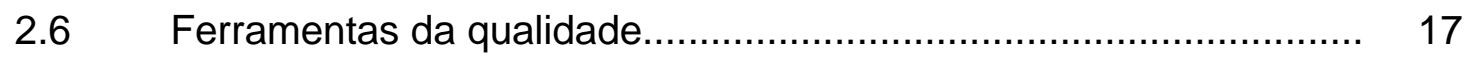

2.6.1 Diagrama de causa e efeito................................................ 18 
2.6.2 Método de qualidade 5W 1H............................................... 20

$2.7 \quad$ Laboratório de análise sensorial................................................. 20

2.8 Sistema de qualidade para o laboratório de análise sensorial......... 23

2.8.1 Estrutura organizacional e responsabilidade............................. 25

2.8.2 Departamento de garantia de qualidade...................................... 26

2.8.3 Localização e instalações......................................................... 26

2.8.4 Equipamentos e materiais................................................. 27

2.8.5 Procedimento operacional padrão............................................ 28

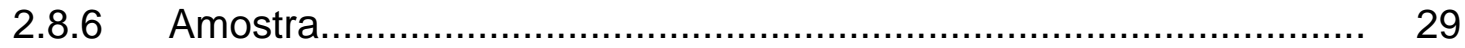

2.8.7 Pessoal - manipulador das amostras...................................... 30

2.8.8 Pessoal - degustador das amostras...................................... 31

2.8.9 9 Higiene e sanitização........................................................... 31

2.8.10 Controle integrado de vetores e pragas urbanas........................... 33

2.8.11 Arquivos de documentos e registros........................................... 33

2.8.12 Monitoramento e avaliação.................................................... 34

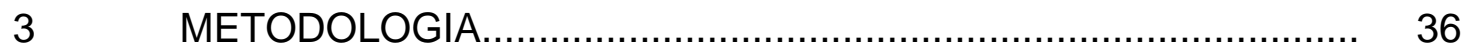

Implementação do sistema de qualidade............................... 36

3.1.1 Apresentação e aprovação do sistema de qualidade..................... 37

3.1.2 Definição da equipe de garantia de qualidade.............................. 37

Capacitação da equipe ................................................ 38

3.1.4 Caracterização do laboratório........................................... 38

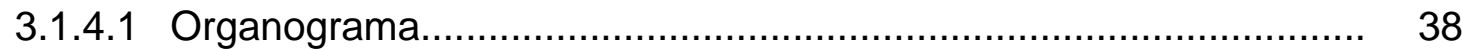


3.1.4.2 Definição funcional.......................................................... 40

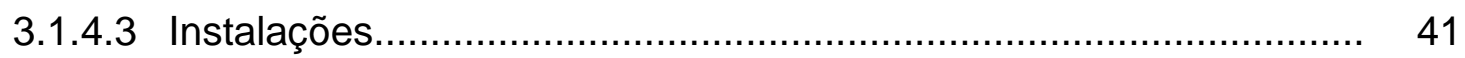

3.1.5 Padronização dos procedimentos.............................................. 43

3.1.6 Treinamento dos colaboradores.............................................. 48

3.1.7 Monitoramento e verificação do sistema de qualidade..................... 52

3.1.7.1 Programação do monitoramento....................................... 52

3.1.7.2 Elaboração da lista de verificação............................................... 54

3.1.7.3 Registro de não conformidades................................................ 56

3.1.7.4 Relatório de monitoramento............................................... 58

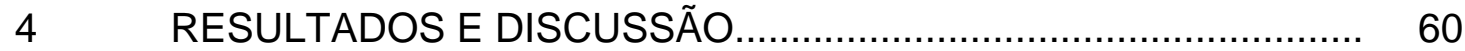

4.1 Resultados da implementação do sistema de qualidade................. 60

4.2 Resultados do processo de monitoramento e verificação................ 65

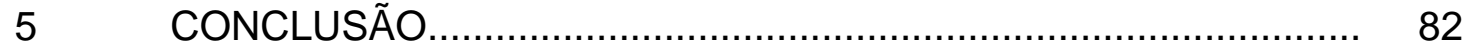

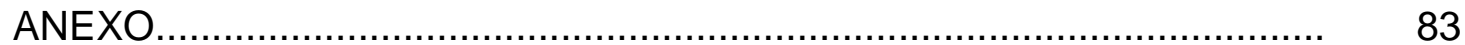

REFERÊNCIAS BIBLIOGRÁFICAS ................................................... 89 


\section{LISTA DE FIGURAS}

Página

1 Esquematização do diagrama de causa e efeito............................... 19

2 Estrutura padronizada do organograma setorial........................... 39

3 Documento de descrição de cargo dos colaboradores..................... 40

4 Documento de caracterização das instalações.................................. 42

$5 \quad$ Estrutura padronizada do POP ..................................................... 44

$6 \quad$ Programação de capacitação e treinamento....................................... 49

$7 \quad$ Demonstrativo de capacitação e treinamento................................ 51

8 Programação de monitoramento e verificação................................ 53

$9 \quad$ Lista de verificação para monitoramento.................................... 55

10 Registro de não conformidade ............................................ 57

11 Relatório de monitoramento............................................ 59

12 Organograma do laboratório de análise sensorial............................ 61

13 Perfil dos resultados das monitorações...................................... 77

14 Relação das não conformidades com os itens do sistema................ 80 


\section{LISTA DE TABELAS}

Página

1 Sistema de qualidade para o laboratório de análise sensorial........... 25

$2 \quad$ Etapas da implementação do sistema de qualidade......................... 36

3 Itens necessários para o cabeçalho do POP.................................... 45

$4 \quad$ Informações necessárias para o corpo do POP - tipo I..................... 46

$5 \quad$ Informações necessárias para o corpo do POP - tipo II..................... 47

$6 \quad$ Equipe de colaboradores do laboratório de análise sensorial............ 62

$7 \quad$ Caracterização do laboratório de análise sensorial........................... 63

$8 \quad$ Procedimento operacional padrão do sistema de qualidade 64

9 Resultados do primeiro processo de monitoração do sistema de qualidade no laboratório de análise sensorial.............................. 65

10 Resultados do segundo processo de monitoração do sistema de qualidade no laboratório de análise sensorial............................ 71

11 Resultados do terceiro processo de monitoração do sistema de qualidade no laboratório de análise sensorial............................... 75

12 Itens do sistema de qualidade afetados na primeira auditoria........... 78

13 Itens do sistema de qualidade afetados na segunda auditoria.......... 78

14 Itens do sistema de qualidade afetados na terceira auditoria........... 79 


\section{LISTA DE SIGLAS, ABREVIATURAS E SÍMBOLOS}

ANVISA - Agência Nacional de Vigilância Sanitária ASTM - American Society for Testing and Materials

$5 \mathrm{~W} 1 \mathrm{H}$ - Metodologia da qualidade 5 (What, Why, When, Where, Who) $1 \mathrm{H}$ (How)

BPF - Boas Práticas de Fabricação

BPL - Boas Práticas de Laboratório

BPM - Boas Práticas de Manufatura

CEATOX - Centros de Controle de Intoxicação

CIP - Controle Integrado de Pragas

DICLA - Divisão de Credenciamento de Laboratórios de Calibração e de Ensaio FSIS - Food Safety and Inspection Service

GIP - Gerenciamento Integrado de Pragas

GLP - Good Laboratory Practices

GMP - Good Manufacturing Practices

INMETRO - Instituto Nacional de Metrologia

ISO - International Organization for Standardization

LAS - Laboratório de Análise Sensorial 
MAAPA - Ministério da Agricultura e do Abastecimento de Produtos Agropecuários

MS - Ministério da Saúde

OECD - Organisation for Economic Co-operation and Development POP - Procedimento Operacional Padrão

PPHO - Procedimentos Padrão de Higiene Operacional

SENAI - Serviço Nacional de Aprendizagem Industrial

SVS - Secretaria de Vigilância Sanitária

SOP - Standard Operation Procedure

SSOP - Sanitation Standard Operating Procedure 


\section{IMPLEMENTAÇÃO DE UM SISTEMA DE QUALIDADE PARA LABORATÓRIO DE ANÁLISE SENSORIAL BASEADO NO SISTEMA DE BOAS PRÁTICAS}

Autora: ANGELA DE FATIMA KANESAKI CORRÊIA Orientadora: Prof ${ }^{\underline{a}}$ Dr $^{\mathrm{a}}$ MARTA HELENA FILLET SPOTO

\section{RESUMO}

Esta dissertação teve como propósito a implementação do Sistema de Qualidade no laboratório de análise sensorial da indústria de alimentos, baseando-se nos princípios das Boas Práticas de Laboratório (BPL) e Boas Práticas de Fabricação (BPF), visando contemplar os aspectos analíticos e processuais. Para isso, fez-se a abordagem das normas fundamentais e dos princípios estabelecidos pelas Boas Práticas, relacionadas com a estrutura organizacional, o gerenciamento das atividades e os critérios necessários para o funcionamento do laboratório de análise sensorial, assegurando a sistemática de padronização e otimização das operações. O laboratório de análise sensorial apresenta características exclusivas que são contempladas nas atividades de manipulação dos alimentos, durante preparação das amostras e atividades analíticas realizadas pelos provadores. 
Em função da especificidade das atividades desenvolvidas, foi necessária a elaboração de procedimentos específicos, levando-se em consideração todos os aspectos inerentes às operações, instalações, equipamentos, análises, produtos e pessoas. Após o processo de implementação do Sistema de Qualidade, foram realizados o monitoramento e a verificação pelo critério de auditorias periódicas, previamente programadas. Os resultados do processo de implementação demonstraram a aplicabilidade do Sistema de Qualidade, na extensão das atividades do laboratório de análise sensorial, em consonância aos princípios das BPL e BPF. O processo de monitoramento e verificação possibilitou, através das atividades de auditorias, promover a estabilização e melhoria do sistema implementado. 


\title{
QUALITY SYSTEM IMPLEMENTATION IN SENSORY ANALYSIS LABORATORY BASED IN GOOD PRACTICES SYSTEM
}

\author{
Author: ANGELA DE FATIMA KANESAKI CORRÊIA \\ Advisor: Prof $^{\underline{a}}$ Dr $^{-}$MARTA HELENA FILLET SPOTO
}

\section{SUMMARY}

This dissertation had like purpose the Quality System implementation in the food industry sensory analysis laboratory, using the principles of Good Laboratory Practices (GLP) and Good Manufacturing Practices (GMP), aiming to contemplate the analytical and processual aspects. For this purpose, was made an examination of basic rules and principles established by the Good Practices related to the organizational structure, the managing activities and the necessary criteria to the sensory analysis laboratory operation, assuring the systematic of the operations standardization and optimization. The sensory analysis laboratory presents exclusive characteristics that are contemplated in the food handling activities, during the samples preparation and the analytical activities carried out by the panelists. Due to the 
specificity of the activities developed, it was necessary the elaboration of specific procedures, taking into account all of the inherent aspects to the operations, facilities, equipments, analysis, products and persons. After the Quality System implementation process, it was carried out the monitoring and verification by the periodic audits criterion, previously programmed. The results of the implementation process showed the Quality System applicability in the range of the sensory analysis laboratory activities, in consonance to the GLP and GMP principles. The monitoring and verification process was possible, by the audits activities, to promote the stabilization and the improvement of the implemented system. 


\section{INTRODUÇÃO}

O enfoque do Sistema de Qualidade, que iniciou nos processos produtivos e suas interfaces, têm se disseminado para outros setores da organização, com objetivo de monitorar a qualidade dos produtos e atender as expectativas dos clientes.

Os motivos destas transformações são: acelerado desenvolvimento tecnológico; globalização da economia; busca de competitividade, diversificação e flexibilidade; conquista de um espaço no mercado; preocupação em transmitir segurança e credibilidade aos clientes.

Desta forma, o enfoque se pulveriza para outros setores que interagem com o setor produtivo e que estão relacionados direta ou indiretamente com a qualidade do produto. A qualidade abrange as funções que vão desde o planejamento de projetos, processos, laboratórios de controle de qualidade, manutenção e serviços (Campos, 2004; Miguel, 2001; Paladini, 2000).

O Sistema de Qualidade em serviços é um dos segmentos de relevante enfoque dentro da organização. Quando implementado em laboratório, possibilita obter dados corretos, permitir a confiabilidade dos laudos emitidos, aumentar a credibilidade e o respeito da comunidade e de seus pares, evitar erros e retrabalhos, facilitar a rastreabilidade, através da adoção de um sistema padronizado (Campos, 2004; Nascimento, 1999). 
Os Sistemas de Qualidade, baseados nos padrões da ISO ou outros de reconhecimento internacional, são descritos de forma genérica, devido a sua ampla abrangência das áreas de aplicação, tornando necessário a obtenção de informações complementares e específicas para determinadas áreas (Holcombe et al., 1999).

De acordo com o mesmo autor, a elaboração de Sistemas de Qualidade específicos, a partir de dois ou mais padrões já existentes, promovem a adequação em função das condições atuais de trabalho.

O atual cenário tem conduzido as indústrias de alimentos a adotarem sistemas específicos de gerenciamento da qualidade, de forma complementar, disseminando para os setores da organização.

O laboratório de análise sensorial é representado por um setor da organização e desempenha papel fundamental na indústria de alimentos e contribui com os argumentos para tomada de decisões. Apresenta características exclusivas que são abordadas em atividades de manipulação de alimentos durante preparação da amostra e atividades analíticas realizadas pelos provadores durante a degustação das amostras.

Desta forma, o presente trabalho parte da premissa de que os atuais Sistemas de Qualidade para laboratórios analíticos, com ênfase nos princípios das Boas Práticas de Laboratório, não estão direcionados de forma abrangente para as atividades específicas do laboratório de análise sensorial.

Sendo assim, os princípios do Sistema de Qualidade podem ser adaptados, incorporados e implementados nas atividades desenvolvidas pelos laboratórios de análise sensorial, a fim de padronizar seus procedimentos de forma sistêmica, levando em consideração os aspectos necessários para a implementação do Sistema de Qualidade.

Neste sentido, para adotar a implementação do Sistema de Qualidade foram levadas em consideração as normas e legislações que regulamentam os princípios das Boas Práticas de Laboratório (BPL) e Boas 
Práticas de Fabricação (BPF), como também as normas específicas para as instalações do laboratório de análise sensorial.

A abordagem deste trabalho contempla as atividades desenvolvidas no processo de implementação do sistema e os resultados da monitoração e checagem do sistema implementado.

O acompanhamento e a checagem do Sistema de Qualidade foram previamente estabelecidos e programados, e realizados pelo método de verificação, após implementação do Sistema de Qualidade.

Os resultados da verificação foram expressos em relatórios e as evidências incompatíveis com o sistema foram apresentadas em forma de não conformidade.

As não conformidades promoveram o estudo em equipe para o levantamento das possíveis causas que geraram as não conformidades e a identificação da causa principal, utilizando como instrumento de auxílio, o diagrama de causa e efeito.

A partir da causa principal, foi elaborada a proposta de ação corretiva, visando mitigar ou eliminar o efeito. Este trabalho foi desenvolvido pela equipe de estudo que utilizou como ferramenta de auxílio o método de qualidade $5 \mathrm{~W} 1 \mathrm{H}$. 


\section{REVISÃO DE LITERATURA}

\subsection{Sistema de qualidade}

A qualidade do ponto de vista das ações, ferramentas e sistemas, é considerada uma questão de relevância para as empresas, preocupadas em diminuir suas incompatibilidades com o ambiente externo e em oferecer produtos e serviços que atendam as necessidades do mercado.

Esta preocupação proporcionou o acesso ao assunto e gerou uma exigência do mercado mundial, considerando que as exigências dos clientes em relação à qualidade dos produtos e serviços promoveram as empresas adoção de técnicas equalizadas e a implementação de sistemas, para se manterem competitivas (Andrade, 2002).

A organização que apresenta como objetivo principal trabalhar com qualidade necessita do reconhecimento das necessidades dos clientes, para desenvolver um Sistema de Qualidade que promova os padrões que atendam às necessidades, estruturar as atividades visando manter os padrões estabelecidos, aplicar a melhoria contínua a partir de uma visão estratégica e com abordagem humanista (Barry, 1974; Campos, 2004; Miguel, 2001).

A implementação do Sistema de Qualidade promove às empresas maior organização das atividades e introduz métodos de trabalhos mais eficientes, através da sistematização das atividades (Malmfors et al., 2004). 
Neste contexto, em função da relevância da aplicação, a abordagem do conceito de Sistema de Qualidade, se apresenta de forma bastante abrangente.

Segundo Deming (1990) o Sistema de Qualidade consiste em uma série de atividades ou funções que trabalham em conjunto na organização, tendo como foco um único objetivo previamente estabelecido.

O Sistema de Qualidade é representado pela estrutura organizacional planejada e documentada, através da utilização de procedimentos constituídos por processos, atividades, responsabilidades e recursos (Prazeres, 1996).

O mesmo autor estabelece que a implementação do Sistema de Qualidade promove a garantia de que projetos, produtos ou serviços satisfaçam às necessidades e às expectativas explícitas e implícitas dos clientes, em consonância com a missão, os objetivos e as metas da organização.

Por outro lado, Hutchins (1994) e Maranhão (1994) consideram que o Sistema de Qualidade representa um conjunto de recursos e regras, a serem implementados adequadamente, com o objetivo de orientar os componentes da organização para executar de forma eficaz as atividades necessárias, tendo como direcionamento o objetivo comum da organização.

Em função da ampla discussão, pode-se considerar que o Sistema de Qualidade, quando implementado na organização, promove os estudos das atividades operacionais, do comportamento humano e de recursos disponíveis, refletindo na padronização dos conceitos, comportamentos e processos.

O Sistema de Qualidade é baseado em princípios que incorporam todas as atividades executadas pela empresa. Conforme demonstra Barquete (2000) esses princípios constam de:

- Satisfação dos clientes: o cliente é a razão da existência de uma empresa, não basta atendê-lo, é preciso encantá-lo; 
- Gerência participativa: liberdade, apoio e estímulo para as pessoas manifestarem opiniões e sugestões;

- Desenvolvimento humano: busca valorizar o ser humano, realização profissional e a motivação;

- Constância de propósitos: estabelece os meios para que se possa atingir o objetivo;

- Aperfeiçoamento contínuo: melhorar sempre, baseando nos princípios de melhoria contínua;

- Gerência de processos: a empresa é constituída de processos menores, que se interligam, na relação entre cliente e fornecedor;

- Delegação: deslocar a responsabilidade de decisão o mais perto da ação;

- Disseminação de informações: proporcionar as informações sobre a missão, estratégias e planos da organização;

- Garantia de qualidade: através de normas e procedimentos, para estabilizar os processos e garantir a qualidade;

- Não aceitar erros: através das ações preventivas, evitar desvios dos padrões estabelecidos.

De acordo com Mello et al. (2002) o Sistema de Qualidade em pequenas organizações provavelmente não se apresenta de forma sistematizada. A operacionalização das atividades está na cabeça das pessoas e na maioria das vezes, não está documentada, em função da quantidade de pessoas envolvidas. Quanto maior a organização, mais pessoas estão envolvidas, portanto maior é a possibilidade de existirem procedimentos, instruções e registros documentados, para conduzir as atividades.

Segundo Barbêdo et al. (2003) a implementação do Sistema de Qualidade é importante para as pequenas e grandes organizações.

$\mathrm{O}$ autor estabelece que as estruturas maiores exijam que os procedimentos sejam cumpridos, em função da inviabilidade de acompanhar as atividades, tornando imprescindível à implementação de Sistema de Qualidade. 
Por outro lado, nas pequenas organizações, a facilidade do acompanhamento das atividades auxilia a garantia da qualidade, mas não se descarta a validez do Sistema de Qualidade para estes ambientes.

O Sistema de Qualidade evoluiu e disseminou para as diversas estruturas organizacionais, como também para as diversas áreas de relevância dentro da própria organização.

A área de prestação de serviço tem apresentado notório reconhecimento dentro da organização, tanto no relacionamento interno como externo. O próximo tópico terá abordagem sobre a qualidade em serviço.

\subsection{Sistema de qualidade em serviço}

Conforme Kotler (1998) serviço é definido como qualquer ato ou desempenho que se possa oferecer de forma essencialmente intangível, podendo ou não estar vinculado a um produto físico.

Segundo Las Casas (1999) os serviços são estabelecidos por atos, desempenho e ações, apresentam características de serem intangíveis, inseparáveis, heterogêneos e simultâneos.

A intangibilidade significa que os serviços são abstratos, pois requerem tratamento individual, ao comparar com os serviços de outras atividades.

A característica de inseparabilidade refere-se ao determinante mercadológico, pois não se pode produzir e estocar serviços, como se faz com os bens.

A heterogeneidade consiste na dificuldade de se manter os resultados dos serviços de forma linear e constante, uma vez que os serviços são produzidos por seres humanos, que é de natureza instável, exigindo desta forma, a aplicação de treinamentos, com o objetivo de padronizar o desempenho pessoal. 
A simultaneidade dos serviços demonstra que a produção e o consumo não possibilitam fragmentação.

O Sistema de Qualidade em serviços compreende a sistemática que estabelece os procedimentos da prestação de serviço e a relação com o cliente externo e interno.

Segundo Miguel (2001) a prestação de serviço, considerada como relação entre cliente e fornecedor, demonstra que os fornecedores devem atender aos requisitos e necessidades dos clientes, através do empenho e responsabilidade de todos os colaboradores da organização.

De acordo com o próprio autor o cliente interno é caracterizado por setores ou departamentos funcionais que se interagem dentro de uma mesma organização, como, produção, suprimentos, manutenção, controle de qualidade, projetos e comercial.

$\mathrm{Na}$ abordagem de cliente interno, os setores dentro de uma mesma empresa, fornecem serviços que atendem aos padrões de qualidade, suprindo as necessidades internas e como conseqüência atendem aos requisitos e necessidades dos clientes externos (Miguel, 2001).

Sendo assim, o Sistema de Qualidade em serviço estabelece a sistematização das atividades desenvolvidas na produção de serviço ou na associação do serviço ao produto.

Nos próximos tópicos serão abordados os princípios das Boas Praticas de Laboratório (BPL), que estão relacionadas às atividades de serviço e das Boas Práticas de Fabricação (BPF), relacionadas ao serviço associado ao produto.

\subsection{Boas práticas de laboratório}

Os laboratórios sofreram grandes transformações, devido ao desenvolvimento tecnológico das inspeções e dos equipamentos de análise, que proporcionaram a introdução de computadores e sistemas automatizados. 
O crescimento da competitividade entre os laboratórios, a tendência de mercado globalizado e os consumidores mais conscientes sobre a qualidade dos produtos disponíveis, também contribuíram para as transformações (Benoliel, 1999).

De acordo com o mesmo autor, a implementação de Sistema de Qualidade em laboratório, é um processo trabalhoso, mas representam inúmeras vantagens, internas e externas, como:

- Melhoria da organização interna, através da formalização e aplicação de procedimentos, que conduz à otimização de processos;

- Definição da função e responsabilidades do pessoal;

- Detecção e correção dos erros;

- Confirmação da competência e qualidade do trabalho;

- Melhoria da imagem do laboratório para os clientes;

- Facilidade para conduzir as reclamações dos clientes.

Segundo Schimidt (1999) o gerenciamento da qualidade no laboratório está relacionado com os processos individuais utilizados na realização dos testes. Considerando as questões relacionadas à organização, equipamentos, necessidades do cliente e quando aplicável às legislações pertinentes ao assunto.

Neste contexto os princípios das Boas Práticas de Laboratório, quando implementado no laboratório, favorecem as atividades de gerenciamento da qualidade.

Conforme o Instituto Nacional de Metrologia (Inmetro, 2003) as Boas Práticas de Laboratório (BPL) é um Sistema de Qualidade, composto por um conjunto de critérios, que diz respeito à organização e às condições sob as quais os estudos em laboratório podem ser planejados, realizados, monitorados, registrados, relatados e arquivados.

De acordo com a Organization for Economic Co-Operation and Development (OECD, 1998) os princípios de Boas Práticas de Laboratório (BPL), foram desenvolvidos para promover a qualidade e a validade de dados 
gerados em testes, usados para determinar a segurança de substâncias químicas e seus produtos.

A princípio, um grupo internacional de especialistas formado pelos países membros da OECD (Organization for Economic Co-Operation and Development) procurou uma harmonização internacional dos métodos de testes e dos princípios de Boas Práticas de Laboratório. Este grupo, liderado pelos Estados Unidos, era formado por: Austrália, Áustria, Bélgica, Canadá, Dinamarca, França, República Federal da Alemanha, Grécia, Itália, Japão, Países Baixos, Nova Zelândia, Noruega, Suécia, Suíça, Reino Unido, Comunidade Econômica Européia, Organização Mundial de Saúde e Organização Internacional para Padronização.

Em 1979, foram desenvolvidos através do Programa Especial de Controle de Substâncias Químicas, os Princípios de Boas Práticas de Laboratório da OECD utilizando práticas administrativas e científicas.

Em 1981, esses princípios de BPL foram formalmente recomendados pelo Conselho da OECD para serem utilizados nos países membros, com propósitos de avaliação e outros usos relativos à proteção do homem e do ambiente (Oecd, 1998).

Os princípios das BPL favorecem a troca de informação e facilitam a comercialização ao mesmo tempo em que contribuem com a proteção da saúde humana e do ambiente (Oecd, 1998).

Segundo a Anvisa (2001) as Boas Práticas de Laboratório são constituídas do programa de garantia de qualidade e procedimentos que descrevem como conduzir as rotinas laboratoriais, ou atividades normalmente não especificadas ou detalhadas no plano de estudo, nas metodologias e manuais.

O Programa de garantia de qualidade faz as referências das atividades desempenhadas pelo laboratório, para atender aos princípios do sistema, envolvendo a caracterização, o pessoal e a sistemática adotada. Por outro lado os procedimentos são elaborados de forma padronizada e sistêmica. 
Apresentam-se redigidos com clareza sem ambigüidade, de fácil entendimento. Estabelecem o procedimento de controle de revisões e aprovação, para garantir a integridade dos dados (Garner et al., 1996).

A regulamentação brasileira que estabelece as Boas Práticas de Laboratório segundo o INMETRO (Instituto Nacional de Metrologia) está contemplada na norma $\mathrm{n}^{\circ}$ 028/03 - Critérios para o credenciamento de laboratórios de ensaio, segundo os princípios das Boas Práticas de Laboratório, de setembro de 2003, pelo Instituto Nacional de Metrologia - DICLA (Divisão de Credenciamento de Laboratórios de Calibração e de Ensaio).

De acordo com o Inmetro (2003) os princípios de BPL são aplicáveis em estudos que dizem respeito ao uso seguro de produtos, com objetivo de avaliar, monitorar e proteger a saúde humana, vegetal, animal e ao meio ambiente, nos seguintes casos:

- Estudos que fundamentam a concessão, renovação ou modificação de registro e pesquisa de produtos químicos, biológicos ou biotecnológicos, tais como produtos farmacêuticos, agrotóxicos, produtos veterinários, cosméticos, aditivos de alimentos, rações e produtos químicos industriais;

- Ensaios envolvendo produtos químicos, biológicos ou biotecnológicos para obtenção de propriedades físicas, químicas e físico-químicas;

- Petição para estabelecimento, modificação ou isenção de tolerância;

- Estudos conduzidos em resposta aos questionamentos de órgãos governamentais;

- Qualquer outra aplicação, petição ou submissão enviada aos órgãos competentes, com a intenção de solicitar a modificação de registro ou outra aprovação requerida, como uma condição de venda ou distribuição;

- Estudos conduzidos em laboratórios de qualquer tipo, próprios ou contratados. 


\subsection{Boas práticas de fabricação}

As Boas Práticas de Fabricação (BPF) ou Good Manufacturing Practices (GMP), são definidas como conjunto de princípios e procedimentos estabelecidos para o correto manuseio de alimentos, abrangendo desde a matéria prima até o produto final, contemplando os controles de processos, produtos, higiene pessoal e sanitização, para garantir segurança e integridade do consumidor (Brasil, 1993; Lopes, 2001).

Também conhecida como Boas Práticas de Manufatura (BPM), asseguram os parâmetros básicos de qualidade com o estabelecimento de procedimentos padronizados e documentados, que devem ser conhecidos e praticados por todos os colaboradores de uma organização.

No cumprimento às Boas Práticas de Fabricação, estão inseridos os Procedimentos Padrão de Higiene Operacional (PPHO) e o Controle Integrado de Pragas (CIP). Devido a sua ampla abordagem em relação aos aspectos operacionais serão abordadas nos próximos tópicos.

\subsubsection{Procedimento padrão de higiene operacional}

De acordo com Food Safety And Inspection Service (FSIS, 2003) os Procedimentos Padrão de Higiene Operacional (PPHO), em seu conceito original Sanitization Standard Operating Procedure (SSOP), são procedimentos padrões adotados para controlar os perigos relacionados à segurança alimentar, no que se refere ao ambiente e instalações.

De acordo com Lopes (2001) os procedimentos descrevem a sistemática das operações de higiene e sanitização, especificando a forma de execução, a freqüência e os responsáveis pelas operações. 
Constituídos por procedimentos documentados os SSOP'S contemplam os aspectos relacionados: qualidade da água; condições de limpeza; prevenção de contaminação cruzada; higiene das mãos e instalações sanitárias; proteção dos alimentos; armazenamento dos produtos químicos; controle das condições de saúde e controle de pragas (Fsis, 2003).

A qualidade da água é considerada um dos principais itens estabelecidos nos procedimentos, definida pela portaria no 518/2004, do Ministério da Saúde (MS), como sendo água para consumo, cujos parâmetros microbiológicos, físicos, químicos e radioativos atendam ao padrão de potabilidade e que não ofereça riscos à saúde (Fsis, 2003).

O sistema de abastecimento de água é constituído pelas instalações, composta por um conjunto de obras civis, materiais e equipamentos, destinados à produção e à distribuição canalizada de água potável, sob a responsabilidade do poder público, mesmo que administrado em regime de concessão ou permissão (Brasil, 2004b).

O controle de qualidade da água é representado pelo conjunto de atividades exercidas por responsáveis pela operação de verificar a potabilidade da água fornecida e assegurar a manutenção desta condição (Brasil, 2004b).

\subsubsection{Controle integrado de pragas}

O Controle Integrado de Pragas (CIP) está contido no sistema de Boas Práticas de Fabricação e representa um conjunto de ações simultâneas, que estabelecem os métodos cíclicos de educação, sanitização, intervenções químicas, biológicas e barreiras físicas, com o objetivo de eliminar os focos de infestações de pragas (Athayde, 2000).

Segundo Brasil (2004a) o controle integrado de vetores e pragas urbanas consiste do sistema que incorpora as ações preventivas e corretivas, destinadas a impedir a atração, abrigo, acesso e proliferação de 
vetores e pragas urbanas que comprometam a qualidade higiênico-sanitária do alimento.

O Controle Integrado de Pragas, também definido como Gerenciamento Integrado de Pragas (GIP), é estabelecido na portaria $\mathrm{n}^{\circ} 09$ de 16 de Novembro de 2000, do MS/ANVISA, como um sistema capaz de incorporar as ações preventivas e corretivas, destinadas a impedir ações de vetores ou pragas. Esta portaria visa minimizar o uso abusivo e indiscriminado de praguicidas, através da utilização de metodologia de controle e critérios que garantam resultados favoráveis sob o ponto de vista higiênico, ecológico e econômico (Brasil, 2000).

Os vetores são considerados artrópodes ou invertebrados que transmitem infecções através do carreamento externo ou interno. O carreamento externo consiste da transmissão passiva ou mecânica dos microrganismos e o carreamento interno representa a transmissão biológica dos microrganismos. Por outro lado, as pragas urbanas consistem de animais que infestam ambientes urbanos, podendo causar agravos à saúde e prejuízos econômicos (Athayde, 2000; Brasil, 2000).

De acordo com o autor, as pragas e vetores representam ameaça à segurança dos produtos alimentícios, e as infestações ocorrem em locais favoráveis à reprodução, com suprimentos de água e alimento.

Conforme estabelece o Serviço de Aprendizagem Industrial (Senai, 2000), o controle integrado de pragas e vetores é realizado de maneira que não interfira adversamente à segurança dos alimentos para o consumo. Consiste de um programa efetivo e documentado, tendo como conteúdo, o nome do operador técnico responsável pelo controle das pragas e vetores, a relação das substâncias utilizadas e suas respectivas concentrações, o método de aplicação, os locais e a freqüência das intervenções.

As Boas Práticas de Fabricação e os trabalhos de educação e treinamento são medidas preventivas adotadas para evitar o desenvolvimento de ambientes favoráveis, que permitam a infestações de pragas e vetores. As 
medidas corretivas compreendem a implantação de barreiras físicas que visam impedir o acesso das pragas e vetores, através da colocação de armadilhas que capturam os infestantes, sendo que tais medidas são complementadas com o controle químico, a partir da utilização de praguicidas por intermédio da desinsetização e desratização (Athayde, 2000; Brasil, 2000).

As empresas especializadas em controlar vetores e pragas urbanas são licenciadas por autoridades competentes, e são responsáveis pelos serviços prestados, utilizando produtos registrados pelo Ministério da Saúde (MS) para o controle de insetos, roedores e de outros animais nocivos à saúde. As controladoras levam em consideração as técnicas de aplicação e as concentrações máximas especificadas, cumprem as instruções do fabricante, contidas no rótulo e seguem a legislação pertinente (Brasil, 2000)

Os desinfestantes domissanitário de uso profissional são produtos de venda restrita a entidades especializadas, pois denominam formulações que se apresentam na forma pronta para uso ou podem estar concentradas para posterior diluição ou outra manipulação autorizada, em local específico e por pessoal especializado das empresas aplicadoras, imediatamente antes de serem utilizadas para a aplicação (Brasil, 2000).

\subsection{Monitoramento e avaliação}

O processo de monitoração e avaliação consiste de atividades designadas para assegurar que a unidade operacional esteja atuando de acordo com os princípios e diretrizes do Sistema de Qualidade (Benoliel, 1999).

A verificação é realizada pela equipe de auditores, composta por membros do departamento de Garantia de Qualidade, provida de formação, treinamento e experiência formalizada para aplicação do monitoramento e inspeção das ações de BPL. Os constituintes da equipe, não apresentam envolvimento na condução das atividades do laboratório, para evitar que a pessoa inspecione sua própria atividade (Inmetro, 2003). 
As avaliações ou auditorias são documentadas e realizadas em intervalos previamente planejados, através de um programa, de acordo com a situação e o grau de importância por parte da área a ser auditada, e dos resultados de verificações anteriores (Calegare, 1999).

O programa é definido por critérios, escopo, freqüência e métodos. Após sua execução, é divulgado e disseminado para os setores envolvidos da organização, em forma de programação de monitoramento e verificação. Geralmente no período de duas semanas que antecedem a data da auditoria, são agendados com o auditado os horários, com o roteiro que os auditores pretendem seguir, para garantir aos auditores que, os responsáveis pelas áreas estejam presentes (Benoliel, 1999; Feigenbaum, 1994; Inmetro, 2003).

No processo de auditoria, após a verificação e checagem, é elaborado um relatório que contempla as informações básicas: data da realização, auditores participantes, escopo, critérios da auditoria e as não conformidades encontradas (Calegare, 1999; Crosby, 1994).

As não conformidades geradas na monitoração desencadeiam um processo em que a área auditada estabelece as ações corretivas para evitar que ocorram reincidências das falhas. O processo de verificação termina quando todas as não conformidades geradas estiverem sidas concluídas, ou seja, quando for verificada que as ações corretivas propostas foram executadas de forma eficaz. O relatório é aprovado pelo coordenador da qualidade ou por um representante dos auditores e pelo responsável da área auditada (Inmetro, 2003; Mello et al., 2002).

Existem três tipos de auditorias a serem utilizadas para o diagnóstico da funcionalidade do Sistema de Qualidade implementado: a auditoria de primeira parte, conhecida como auditoria interna é conduzida pela organização, ou em seu nome, para propósito interno; a auditoria de segunda parte, também conhecida por auditoria de fornecedor, é realizada pelos clientes internos e externos, fornecedores e parceiros; a auditoria de terceira parte ou 
externa é realizada por uma entidade externa à organização e sem nenhuma relação com esta, como por exemplo, uma certificadora ou outras instituições.

As auditorias de segunda e terceira parte podem aumentar o grau de objetividade no conhecimento da empresa sob a perspectiva do cliente. Por outro lado, as auditorias internas são utilizadas para determinar se o Sistema de Qualidade se apresenta de acordo com as disposições planejadas e com os requisitos estabelecidos. Fornecem informações para análise crítica da administração e para tomadas de ações corretivas, preventivas ou de melhoria, e são responsáveis pela formação da autodeclaração de conformidade pela organização. A equipe de auditores internos é constituída pelos próprios colaborares, que são capacitados com curso de formação de auditores internos. Os auditores não podem auditar seus próprios setores, para garantir a objetividade e imparcialidade no processo (Garvin, 1988; Mello et al., 2002; Miguel, 2001).

Neste sentido, as atividades envolvidas no processo de monitoramento e verificação, estão relacionadas com a checagem da funcionalidade do sistema implementado, através de procedimentos sistematizados, tendo como complemento a aplicação de técnicas específicas, denominadas de ferramentas da qualidade. No próximo item serão abordadas as ferramentas usualmente utilizadas, na implementação de sistemas.

\subsection{Ferramentas da qualidade}

As ferramentas da qualidade, também denominadas como ferramentas tradicionais da qualidade, são freqüentemente utilizadas no processo de implantação de programas de qualidade pela organização (Miguel, 2001).

Conforme Paladini (1997) as ferramentas são métodos estruturados, utilizados na implementação de sistemas, compostos por 
dispositivos, procedimentos gráficos, numéricos ou analíticos, formulações práticas, esquemas de funcionamento e mecanismos de operação.

$\mathrm{Na}$ implementação de Sistema de Qualidade é primordial a aplicação de técnicas, que, pela simplicidade, facilidade de utilização e obtenção de resultados notáveis, demonstram que o Sistema de Qualidade pode passar da teoria à prática. Essas ferramentas são de fundamental importância, pois irão contribuir para o sucesso do programa a ser implementado (Paladini, 1997).

Segundo o autor, as técnicas evoluíram bastante, passaram de modelos estatísticos elementares para matrizes, que, embora pareçam complexas pela abrangência e diversidade de informações, são de simples compreensão, fácil manipulação e produzem resultados bastante relevantes (Paladini, 1997).

O diagrama de causa e efeito, considerado como uma das ferramentas tradicionais da qualidade, será abordado no próximo item.

\subsubsection{Diagrama de causa e efeito}

O diagrama de causa e efeito também conhecido como diagrama de espinha de peixe ou diagrama de Ishikawa é uma ferramenta efetiva para identificar as raízes do problema. Utilizado na identificação das possíveis causas da ocorrência da não conformidade, realiza as buscas sistemáticas de fatos, gerando discussões em grupo e registrando todas as causas potenciais que possam resultar no efeito (Slack et al., 2002).

O diagrama consiste de uma forma gráfica de metodologia de análise, que representa as possíveis influências ou causas que geram um determinado problema ou efeito (Ishikawa, 1994).

É representado de forma similar à espinha de peixe. O eixo principal demonstra um fluxo de informações, e as espinhas que para ele se dirigem representam as contribuições secundárias ao processo sob análise. 0 
diagrama é segmentado em seis categorias: materiais; máquina; medida; meio ambiente; mão-de-obra e método, conforme ilustrado na Figura 1. Em sua forma gráfica, promove a facilidade para a identificação e análise das causas mais prováveis (Ambrozewicz, 2003; Miguel, 2001; Paladini, 1997).

\section{MANOSAS}

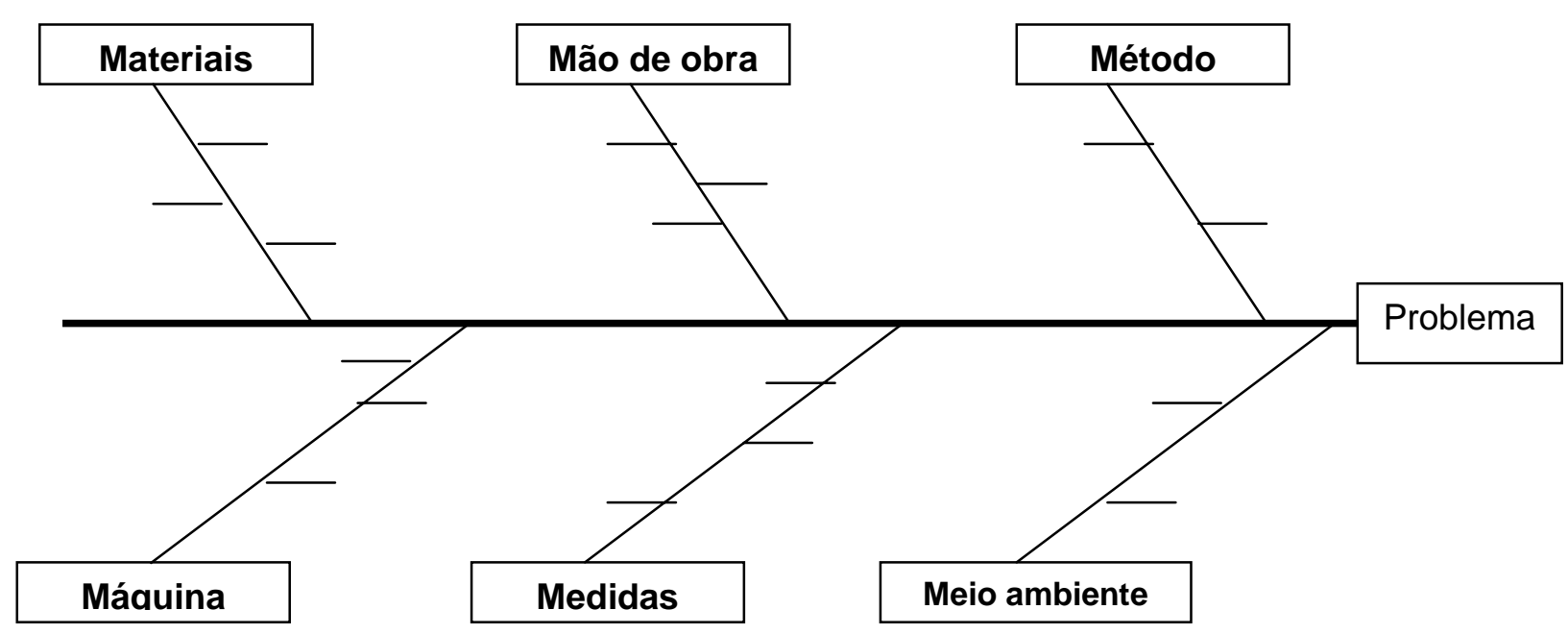

Figura 1 - Esquematização do diagrama de causa e efeito

Após o levantamento das possíveis causas e da identificação da causa principal que proporcionou o efeito, é desenvolvida a proposta do plano de ação corretiva, utilizando como auxílio o método de qualidade $5 \mathrm{~W} 1 \mathrm{H}$, que será apresentado no próximo item. 


\subsubsection{Método de qualidade $5 \mathrm{~W} 1 \mathrm{H}$}

O método de qualidade 5W 1H (What, Why, When, Where, Who e How) é utilizado como instrumento de auxílio na elaboração da proposta da ação corretiva. De simplicidade na aplicação, serve como guia para conduzir o processo, em que a ação proposta será definida a partir da causa principal, que proporcionou a falha. Este trabalho é desenvolvido e estabelecido por uma equipe de estudo (Campos, 2004; Paladini, 2000).

Segundo Campos (2004) a aplicação do método, consiste na discussão do grupo envolvido na elaboração do plano de ação, que a partir da causa principal, que provocou o efeito, deverá estabelecer os 5W (What, When, Who, Where, Why) e $1 \mathrm{H}$ (How):

- Definir o que será feito (What);

- Definir quando será feito (When);

- Definir quem fará (Who);

- Definir onde será feito (Where);

- Estabelecer por que será feito (Why);

- Detalhar como será feito (How).

De acordo com Ambrozewicz (2003) o método consiste de excelente check list para os processos complexos, pois apresenta facilidade para identificar as variáveis, causa e objetivo a ser alcançado, garantindo que todos os ângulos sejam abordados de forma a exaurir as questões sobre o assunto.

\subsection{Laboratório de análise sensorial}

A evolução da análise sensorial como ferramenta de controle da qualidade dos produtos alimentícios se formalizou com os conceitos 
fundamentais, em utilizar equipe de provadores e laboratório apropriado, para avaliar as influências das variáveis de processo nas propriedades sensoriais dos alimentos independente de preferências, e correlacionar os parâmetros sensoriais com as propriedades físicas e químicas dos alimentos, selecionar e treinar a equipe de degustadores, quando pertinente (Faria, 2002).

Por outro lado, a elaboração dos testes de análise sensorial, com a participação de provadores treinados e análises complexas, nem sempre apresentam de forma prática, acessível e desejável (McEwan, 1999).

Portanto, a necessidade de utilização de métodos mais simples, para análise de produtos, que representam fácil aplicabilidade, tem-se desenvolvido metodologias de avaliação, com o objetivo de conduzir testes válidos e confiáveis e que forneçam informações necessárias à tomada de decisão (Faria, 2002; McEwan, 1999).

Segundo Meilgaard et al. (1999) o sucesso da análise sensorial depende da habilidade em otimizar os fatores fundamentais: definir o que se deseja medir, através da medida de sensações e percepções; planejar o teste com base no conhecimento prévio das possibilidades de erros, para diminuir a subjetividade e minimizar a quantidade de testes; conhecer os limites dos degustadores e quando apropriado, trabalhar com provadores selecionados e treinados; e interpretar os resultados e utilizar a estatística como ferramenta de análise.

As análises sensoriais, quando ocorrem em laboratórios adequados, possibilitam o controle das condições ambientais e favorecem a promoção dos estímulos (Graaf et al., 2005).

Conforme o mesmo autor o controle das condições experimental, reduz os erros sistemáticos, que são promovidos por influência do meio.

Neste contexto, a obtenção de resultados confiáveis em uma avaliação sensorial, é fundamental os controles do ambiente, instalações, produto, equipamentos, utensílios, preparadores de amostras e provadores. 
$\mathrm{Na}$ análise sensorial a consistência dos resultados obtidos por diferentes provadores é um assunto de fundamental relevância, principalmente para as indústrias (McEwan, 1999).

Conforme demonstra o mesmo autor, o crescimento da exigência para que os laboratórios de análise sensorial demonstrem, que seus resultados possam ser repetitivos, quando aplicados em outros laboratórios, promoveram a crescente busca em trabalhar de forma sistematizada, em função da necessidade de demonstrar a confiança nos resultados apresentados pela equipe de provadores.

Esta discussão sobre o assunto promoveu a necessidade da realização de estudos. Um dos exemplos foi com o chocolate, que foi submetido à análise descritiva realizada por equipe de provadores britânicos e noruegueses, apresentaram os mesmos resultados, em termos de diferenças e similaridades (McEwan, 1999).

O autor demonstrou outro trabalho realizado com um grupo constituído de várias indústrias, que aplicaram a análise sensorial em um determinado produto de cereal, para suas equipes de provadores e os resultados obtidos da análise de comparação múltipla e análise de perfil, promoveu as indústrias à possibilidade da realização de estudos para verificar a confiabilidade dos resultados apresentados pelos seus provadores treinados.

Neste contexto, a importância da utilização da análise sensorial por parte das indústrias de alimentos e por pesquisadores, na condução dos estudos, tem notório reconhecimento da aplicabilidade.

Pois em pesquisas realizadas, foram constatadas que, os fatores fisiológicos e sensoriais são fundamentais e de grande importância e são considerados como fatores decisórios, para a escolha dos alimentos e muitas vezes, são os responsáveis pela mudança do hábito de consumo (Kozlowska et al., 2002). 


\subsection{Sistema de qualidade para o laboratório de análise sensorial}

O Sistema de Qualidade com base nos princípios das Boas Práticas de Laboratório (BPL), está contemplado na Norma nº 028/2003 Critérios para o credenciamento de laboratórios de ensaio segundo os princípios das Boas Práticas de Laboratório, do Instituto Nacional de Metrologia/ Divisão de Credenciamento de Laboratórios de Calibração e de Ensaio.

A abordagem das Boas Práticas de Fabricação (BPF) no Sistema de Qualidade é estabelecida pelas seguintes portarias:

- Portaria no 1428 de 26 de novembro de 1993 - Diretrizes gerais para o estabelecimento de boas práticas de produção e prestação de serviços na área de alimentos do Ministério da Saúde;

- Portaria no 326 de 30 de julho de 1997 - Regulamento técnico sobre as condições higiênico-sanitárias e de boas práticas de fabricação para indústrias de alimentos, do Ministério da Saúde (MS)/Secretaria de Vigilância Sanitária (SVS);

- Portaria no 368 de 04 de setembro de1997 - Obrigatoriedades para a manipulação de alimentos do Ministério da Agricultura e do Abastecimento de Produtos Agropecuários (MAAPA).

Como complemento aos princípios das Boas Práticas de Laboratório (BPL) e Boas Práticas de Fabricação (BPF), determinados itens específicos estão contemplados em outros regulamentos:

- Portaria no 09 de 16 de novembro de 2000 - Norma técnica para empresas prestadoras de serviço em controle de vetores e pragas urbanas, do Ministério da Saúde/ Secretaria de Vigilância Sanitária;

- Resolução no 275 de 21 de outubro de 2002 - Regulamento técnico de procedimentos operacionais padronizados aplicados aos estabelecimentos produtores de alimentos, da Agência Nacional de Vigilância Sanitária/ Ministério da Saúde; 
- Portaria no 518 de 25 de março de 2004 - Norma de qualidade da água para consumo humano, do Ministério da Saúde;

- Resolução nº 216 de 15 de setembro de 2004 - Regulamento técnico de Boas Práticas para serviço de alimentação, da Agência Nacional de Vigilância Sanitária.

As normas específicas para o laboratório de análise sensorial estão estabelecidas na:

- ASTM E 480/1984 - Standard pratice for establishing conditions for laboratory evaluation of foods and beverages da American Society for Testing and Materials;

- ISO 8586-1/ 1993 - Sensory analysis general guidance for the selection, training and monitoring of assessors, da International Organization for Standardization;

- ISO 8589/1988 - Sensory analysis general guidance for the design of test rooms, da International Organization for Standardization.

Para melhor visualização, o Sistema de Qualidade específico para o laboratório de análise sensorial, está contemplado em seus itens a relação com os princípios das normas vigentes, apresentados na Tabela 1. 
Tabela 1. Sistema de qualidade para o laboratório de análise sensorial

\begin{tabular}{lcccc}
\hline \multirow{2}{*}{ Itens do sistema de qualidade } & \multicolumn{4}{c}{ Princípios das normas } \\
\cline { 2 - 5 } Estrutura organizacional e responsabilidade & BPL & BPF Outros Sensorial \\
Departamento de garantia de qualidade & X & & & \\
Localização e instalações & $X$ & $X$ & $X$ & $X$ \\
Equipamentos e materiais & $X$ & $X$ & $X$ & $X$ \\
Procedimento operacional padrão & $X$ & $X$ & $X$ & \\
Amostra & $X$ & & & $X$ \\
Pessoal - manipulador das amostras & $X$ & $X$ & $X$ & $X$ \\
Pessoal - degustador das amostras & & & & $X$ \\
Higiene e sanitização & $X$ & $X$ & $X$ & \\
Controle integrado de vetores e pragas urbanas & $X$ & $X$ & $X$ & \\
Arquivos de documentos e registros & $X$ & & & \\
Monitoramento e avaliação & $X$ & $X$ & $X$ & \\
\hline
\end{tabular}

\subsubsection{Estrutura organizacional e responsabilidade}

A estrutura organizacional representa a definição clara e objetiva da estrutura funcional da organização. Todo colaborador deve ter conhecimento de suas responsabilidades e ter um lugar definido na estrutura funcional, de forma que sejam mantidos atualizados os registros das qualificações, treinamentos, experiência e descrição de cargos. Quando necessário, são providenciados treinamento e reciclagem, de acordo com a programação estabelecida (Inmetro, 2003).

Os colaboradores em todos os níveis são a essência da organização, pois seu total envolvimento e comprometimento possibilitam, o desenvolvimento de suas habilidades, promovendo o crescimento pessoal que é traduzido em benefícios para a empresa (Mello et al., 2002). 
O envolvimento e comprometimento da alta direção são essenciais para o funcionamento e o sucesso do programa, mas é primordial que atinja todos os níveis hierárquicos da organização (Mello et al., 2002).

\subsubsection{Departamento de garantia de qualidade}

Unidade responsável pelo Sistema de Qualidade na organização é constituída por uma pessoa ou um grupo de pessoas, com formação, treinamento e experiência, formalizados para a aplicação do monitoramento e inspeções das ações de Boas Práticas de Laboratório (Inmetro, 2003).

O coordenador é o responsável pelo sistema e se reportará à alta direção da organização. É uma pessoa motivada, com capacidade de liderar e trabalhar em equipe, com conhecimento técnico de implantação de sistema e apresenta relacionamento e acesso direto com os variáveis níveis hierárquicos (Hajdenwurcel, 2002; Inmetro, 2003).

O coordenador deve desenvolver um ambiente para que toda a equipe possa estar envolvida e comprometida no propósito de atingir as metas. Deve compreender e responder às mudanças do ambiente externo, atender as necessidades de todas as partes interessadas, delegar tarefas, envolver as pessoas para alcançar os objetivos e ser proativo (Mello et al., 2002).

\subsubsection{Localização e instalações}

A localização do laboratório deve ser estrategicamente planejada, a instalação deve situar em zonas isentas de odores indesejáveis, fumaça, pó, poeira e outros contaminantes físicos (Brasil, 1997a; Inmetro, 2003).

De acordo com a American Society for Testing and Materials (Astm, 1984), as cabines de degustação devem garantir a individualidade de 
julgamento do provador, apresentar sistema de exaustão ou atmosfera com pressão positiva, e prover luz branca e colorida, para mascarar a cor da amostra quando necessário.

A disposição das cabines deve ser de forma que não haja contato com a área de manipulação ou preparação das amostras, contendo apenas uma janela de comunicação e passagem das amostras, International Organization for Standardization (Iso, 1988).

Segundo a portaria no 368/1997, do Ministério da Agricultura e do Abastecimento de Produtos Agropecuários (MAAPA), os pisos das instalações devem ser de material resistente, impermeável, lavável, de fácil limpeza e antiderrapante, não devem apresentar frestas e os ralos devem ser do tipo sifão. As paredes devem ser revestidas de materiais impermeáveis e laváveis, de cores claras, lisas, sem frestas e fáceis de limpar. Os ângulos entre as paredes e o piso devem ser abaulados para facilitar a limpeza. O teto deve ser construído de modo que seja de fácil limpeza e que impeça o acúmulo de sujeira.

\subsubsection{Equipamentos e materiais}

Os equipamentos utilizados no laboratório devem estar acompanhados de informações necessárias para o correto funcionamento, devem ser limpos e inspecionados periodicamente, submetidos à manutenção preventiva e calibração, quando pertinente. Quando o equipamento for apropriado à calibração, deve possibilitar a rastreabilidade das medidas de grandezas físicas e apresentar um registro denominado certificado de calibração, emitido por empresas especializadas (Inmetro, 2003).

Os materiais utilizados para a manipulação da amostra, que possam entrar em contato com o alimento, devem ser confeccionados de material atóxico, que não transmita odor e sabor, que sejam resistentes à corrosão e capazes de resistir a repetidas operações de limpeza e desinfecção. 
As superfícies devem ser lisas e isentas de rugosidade e frestas e outras imperfeições que possam comprometer o processo de higienização (Brasil, 1997a; Brasil, 1997b).

\subsubsection{Procedimento operacional padrão}

São procedimentos documentados que descrevem como conduzir os ensaios e as atividades de rotina do laboratório (Inmetro, 2003).

Também definidos como Standard Operating Procedure (SOP), são procedimentos descritos para assegurar que todos os colaboradores que executam a mesma atividade, conduzam o trabalho da mesma maneira (Garner et al., 1996).

A padronização dos procedimentos operacionais de forma simples e objetiva consiste na elaboração do esboço da seqüência correta das operações, descrita de forma resumida, contendo os passos críticos de forma pictórica, para facilitar o entendimento (Campos, 2004).

Ao redigir os procedimentos, são levadas em consideração as particularidades específicas do laboratório. O Procedimento Operacional Padrão deve ser redigido por pessoa com experiência e conhecimento das atividades, tendo aprovação da gerência do laboratório e dotada de sistemática de controle das revisões (Garner et al., 1996).

Conforme descrito na resolução no 275/2002, da Agência Nacional de Vigilância Sanitária, o Procedimento Operacional Padronizado (POP) é constituído por documento escrito de forma objetiva, que estabelece instruções seqüenciais para a realização de operações rotineiras e específicas.

Os estabelecimentos processadores de alimentos devem desenvolver, implementar e manter os procedimentos para as atividades de: higienização das instalações, equipamentos, móveis e utensílios; controle de potabilidade da água; higiene e saúde dos manipuladores; manejo dos resíduos; manutenção preventiva e calibração de equipamentos; controle 
integrado de vetores e pragas urbanas; seleção das matérias-primas, ingredientes e embalagens; e programa de recolhimento de alimentos (Brasil, 2002).

\subsubsection{Amostra}

A amostra consiste de produtos alimentícios ou materiais que são encaminhados para análise, sendo necessário manter o registro de caracterização da amostra, data de recebimento, prazo de validade, quantidade recebida, quantidade utilizada nos testes e condições de armazenamento (Inmetro, 2003).

O produto alimentício pode ser considerado como toda substância ou mistura, nos estados, sólido, líquido, pastoso ou qualquer outra forma, podendo ser apresentado como: alimento "in natura", de origem vegetal ou animal, cujo consumo imediato exija-se apenas a remoção da parte não comestível e tratamentos indicados para higienização; alimento semiprocessado requer uma preparação antes de ser disponibilizado para o consumo; ou alimento processado, contido em uma embalagem, pronto para ser consumido (Brasil, 1997b; Brasil, 2002; Brasil 2004a).

Conforme estabelecidas na portaria $\mathrm{n}^{0}$ 326/1997, do Ministério da Saúde/Secretaria de Vigilância Sanitária e na resolução nº 275/2002 da Agência Nacional de Vigilância Sanitária, as operações de processamento dos alimentos devem ser realizadas sem demoras inúteis e em condições que excluam possibilidades de contaminação, deterioração e proliferação de microrganismos patogênicos e deteriorantes.

A amostra submetida a analise deve ser processada ou preparada em condições que atendam aos requisitos de qualidade e segurança do produto, em conformidade com as Boas Práticas de Fabricação. 


\subsubsection{Pessoal - manipulador das amostras}

As normas que estabelecem as diretrizes para os manipuladores de produtos alimentícios estão descritas nas portarias $\mathrm{n}$ 326/1997, do MS/ SVS e nํㅜ 368/1997, do MAAPA e nas resoluções nº 275/2002 e $n^{0}$ 216/2004, da ANVISA.

O manipulador das amostras deve ser instruído com relação às práticas higiênico-sanitárias, adotando as precauções necessárias para evitar a contaminação dos alimentos (Brasil, 2002; Brasil, 2004a).

A constatação ou suspeita de que o manipulador apresente alguma enfermidade ou problema de saúde que possa resultar na transmissão de perigo aos alimentos, deve impedi-lo de entrar na área de manipulação (Brasil, 1997b; Brasil, 2002).

Os manipuladores de alimentos devem submeter-se aos exames médicos e laboratoriais periódicos para avaliação das condições de saúde (Brasil, 1997b; Brasil, 2004a).

A pessoa que executa atividade numa área de manipulação de alimentos deve, enquanto em serviço, lavar as mãos de maneira freqüente e cuidadosa com agente de limpeza autorizado pelo Ministério da Saúde (Brasil, 1997a; Brasil 1997b; Brasil, 2004a).

As mãos devem ser lavadas antes do início do trabalho, imediatamente após o uso do sanitário, após a manipulação de material contaminado e todas as vezes que forem necessárias. A instrução do processo de lavagem das mãos deve estar documentada e acessível aos colaboradores (Brasil, 1997a; Brasil 1997b; Brasil, 2002).

O operador da área de manipulação de alimentos deve manter higiene pessoal esmerada e usar roupa e touca protetoras e sapatos fechados. Deve estar desprovido de objetos de adorno pessoal como, brinco, relógio, perfume, batom, unhas compridas e esmalte (Brasil, 1997a; Brasil 1997b; Brasil, 2004a). 
Nas áreas de manipulação de alimentos deve ser proibido todo o ato que possa originar contaminação, como: espirrar, fumar, tossir, coçar a cabeça, enfiar o dedo na boca ou no nariz, bem como outras práticas não higiênicas (Brasil 1997b; Brasil, 2002; Brasil, 2004a).

\subsubsection{Pessoal - degustador das amostras}

A equipe de degustadores consiste de um grupo de pessoas de número variável, dependendo do objetivo e do tipo de teste sensorial a ser aplicado, que irão degustar as amostras e expressar seus julgamentos (Faria, 2002).

A necessidade de utilizar provadores selecionados e treinados vai depender do tipo de teste a ser realizado. No caso de testes afetivos não é necessária a utilização de equipe selecionada e treinada. Para os testes discriminativos e descritivos são recomendadas, a realização de recrutamento, seleção e treinamento dos provadores (Faria, 2002; Iso, 1993).

Para todos os testes, os provadores devem ser instruídos quanto aos procedimentos da análise, o uso do questionário e o objetivo do teste. Devem estar em boas condições de saúde física, emocional e psicológica. Qualquer alteração percebida no provador, que possa proporcionar influência indesejável no resultado do teste, deve ser registrada no relatório e considerada no final da avaliação (Faria, 2002; Iso, 1993).

\subsubsection{Higiene e sanitização}

Os procedimentos de higiene e sanitização do laboratório de análise devem ser descritos detalhadamente nos Procedimentos Operacionais Padronizados (Brasil, 1997a; Brasil, 1997b).

Nos procedimentos, devem ser descritos os métodos utilizados, a freqüência, requisitos para os colaboradores, condições de uso, 
concentração, temperatura, tempo, ação mecânica, produtos e local apropriado para a operação (Brasil, 1997b; Brasil, 2002; Brasil, 2004a).

As pessoas envolvidas nas atividades devem ser treinadas para os procedimentos estabelecidos.

A etapa de higienização dos equipamentos e utensílios deve ocorrer em áreas próprias, dotadas de pia e água corrente (Brasil, 2004a).

Os produtos de higienização devem obedecer à legislação vigente, devendo os desinfetantes utilizados serem registrados no Ministério da Saúde. Os produtos devem ser acompanhados de fichas técnicas e dados de segurança fornecidos pelo fabricante (Brasil, 1993; Brasil, 1997a; Brasil, 2002).

Na manipulação de alimentos deve ser utilizada água potável, com pressão e temperatura conveniente à aplicação e protegida de contaminação, através do controle semestral da potabilidade da água (Brasil, 1997a; Brasil, 1997b).

O reservatório de água deve ser constituído por materiais atóxicos e inodoro para que não comprometam a qualidade da água, deve apresentar superfície lisa, resistente e impermeável, isento de rachaduras, vazamentos, infiltrações e descascamentos. Provido de extravasor na sua parte superior e protegido contra inundações (Brasil, 2004b).

O processo de higienização do reservatório de água deve ocorrer no momento da sua instalação, numa periodicidade máxima de seis meses ou na ocorrência de acidentes que possam contaminar a água (Brasil, 204b).

O resíduo sólido gerado pelo laboratório deve estar acondicionado em recipientes próprios, com discriminação claramente definida para resíduos secos e orgânicos (Brasil, 1997b; Brasil, 2002; Brasil, 2004a).

Os recipientes devem ser providos de identificação e tampa pedal, revestidos com saco plástico resistente e esvaziados sempre que necessário (Brasil, 1997b; Brasil, 2002; Brasil, 2004a). 


\subsubsection{Controle integrado de vetores e pragas urbanas}

O controle de vetores e pragas urbanas está disposto nas portarias $n^{\circ}$ 326/1997 e $n^{\circ}$ 09/2000 do MS/ SVS, como também na portaria $n^{\circ}$ 368/1997, do MAAPA e nas resoluções nํㅜ 275/2002 e nํㅜ 216/2004, da ANVISA.

As medidas de controle de pragas compreendem o tratamento com agentes químicos, biológicos e físicos sob a supervisão técnica, para identificar, avaliar e interferir nos perigos potenciais à saúde (Brasil, 1997a; Brasil, 1997b).

As empresas controladoras de vetores e pragas urbanas devem ser licenciadas por autoridade sanitária do Estado ou Município e especializadas na manipulação e aplicação de desinfestantes domissanitários, devidamente registrados no Ministério da Saúde (Brasil, 2000).

As empresas controladoras de vetores e pragas devem emitir um documento ao final do serviço executado, com a assinatura do responsável técnico, constando as seguintes informações: pragas-alvo; nome do desinfestante aplicado; composição qualitativa do produto; quando o produto for composto, as proporções das substâncias; quantidade total empregada por área; nome do antídoto a ser utilizado em caso de acidente, telefone dos CEATOX - Centros de Controle de Intoxicação (Brasil, 2000).

\subsubsection{Arquivos de documentos e registros}

Os arquivos devem ser estruturados e equipados para 0 acondicionamento e armazenamento seguro, garantindo a integridade dos documentos e registros. O material retido nos arquivos deve ser indexado de forma ordenada para promover a rápida recuperação. O período de retenção dos materiais deve ser previamente estabelecido e registrado, bem como sua inclusão, retirada e devolução. Somente o pessoal designado e autorizado 
formalmente pela gerência tem o acesso aos arquivos de documentos e registros (Inmetro, 2003).

O relatório final consiste de um registro científico, que descreve as informações inerentes ao estudo realizado. Redigido de forma padronizada, contempla em seu conteúdo: o título descritivo da análise; identificação do teste por nome ou código; identificação e caracterização da substância teste; informações sobre a unidade operacional e pessoal envolvida nos estudos; data do início e final dos ensaios; referência do material e métodos utilizados; sumários dos resultados com cálculos e quando pertinentes os métodos estatísticos; avaliação e discussão dos resultados; quando apropriada, a conclusão (Anvisa, 2001; Inmetro, 2003).

O responsável pelo laboratório deve assinar o relatório final para garantir que o estudo foi conduzido de acordo com os princípios estabelecidos. Recomenda-se a utilização do Sistema Internacional de Unidades e as referências das análises devem ser validadas e reconhecidas oficialmente (Anvisa, 2001; Inmetro, 2003).

\subsubsection{Monitoramento e avaliação}

O monitoramento consiste da atividade do departamento de garantia de qualidade, realizada pela equipe de auditores, definidos em programação, designado para assegurar por meio de auditorias ou avaliação, que a operacionalização do laboratório esteja conforme o Sistema de Qualidade adotado, com relação aos princípios das Boas Práticas (Inmetro, 2003).

As pessoas que irão auditar o laboratório não devem estar envolvidas na condução das atividades do laboratório, a fim de evitar o conflito de interesse entre as atividades desenvolvidas e as ações de inspeções. A equipe deve ter treinamento, especialização e experiência necessária para desempenhar sua função, precisa estar familiarizada com os procedimentos 
referentes à condução da avaliação, habilidade para entender os conceitos básicos envolvendo as atividades que estão sendo monitoradas e um amplo entendimento dos conceitos e dos princípios das Boas Práticas (Inmetro, 2003). 


\section{METODOLOGIA}

\subsection{Implementação do sistema de qualidade}

A implementação do Sistema de Qualidade no laboratório de análise sensorial foi realizada de forma gradativa e sistêmica, com o envolvimento e participação de todos os colaboradores da organização. As etapas de implementação foram desenvolvidas conforme a Tabela 2.

Tabela 2. Etapas da implementação do sistema de qualidade

\begin{tabular}{cl}
\hline Etapas & \multicolumn{1}{c}{ Descrição das atividades } \\
\hline 1 & $\begin{array}{l}\text { Apresentação e aprovação para implementação do Sistema de } \\
\text { Qualidade }\end{array}$ \\
2 & Definição da equipe de Garantia de Qualidade \\
3 & Capacitação da equipe \\
4 & Caracterização do laboratório de análise sensorial \\
5 & Padronização dos procedimentos \\
6 & Treinamento dos colaboradores \\
7 & Monitoramento e verificação do sistema \\
\hline
\end{tabular}




\subsubsection{Apresentação e aprovação do sistema de qualidade}

O Sistema de Qualidade baseado nos princípios de Boas Práticas foi apresentado à alta direção da empresa, composta por diretores e gerentes. A apresentação caracterizou-se de uma reunião com a explanação de forma consistente e objetiva dos tópicos relevantes do Sistema de Qualidade específico para o laboratório de análise sensorial, como: caracterização de Boas Práticas de Laboratório e Boas Práticas de Fabricação; importância da atuação do laboratório de análise sensorial na indústria de alimentos e proposta para implementação do Sistema de Qualidade específico para o laboratório de análise sensorial.

O próximo passo foi avaliação e aprovação da proposta pela equipe que compõe a alta direção da organização, através de uma análise crítica, para verificar se apresentava em consonância com os objetivos e metas da empresa.

\subsubsection{Definição da equipe de garantia de qualidade}

A equipe de garantia da qualidade foi indicada pela alta direção da organização. Composta por um representante da empresa, denominado coordenador da qualidade e por mais 4 colaboradores, denominados auditores internos.

O coordenador da qualidade e os auditores foram escolhidos por apresentarem as características pessoais, necessárias para o desempenho das funções. 


\subsubsection{Capacitação da equipe}

O coordenador da qualidade e a equipe de auditores foram submetidos à capacitação e treinamentos específicos para a implementação do Sistema de Qualidade no laboratório de análise sensorial.

No treinamento específico foram abordados os conceitos básicos, os objetivos e vantagens do sistema, bem como as abordagens técnicas, como auxílio no desenvolvimento das habilidades, atitudes e desempenho.

\subsubsection{Caracterização do laboratório}

As informações contidas na caracterização do laboratório representavam as instalações, o pessoal e as atividades desenvolvidas, com relação aos princípios estabelecidos pelo Sistema de Qualidade específico para o laboratório de análise sensorial.

Estas informações serviram de base para a sistematização do escopo e estabeleceram os princípios para o desenvolvimento do processo de implementação.

\subsubsection{Organograma}

O organograma do laboratório de análise sensorial foi definido como um documento pertencente ao Sistema de Qualidade, em função de apresentar as informações que visualizavam o escopo do sistema a ser implementado.

A estrutura padrão foi desenvolvida para a elaboração do organograma setorial da organização (Figura 2). 
$\mathrm{Na}$ estrutura desenvolvida foi inserida a indicação do setor, data da elaboração ou atualização, número da revisão vigente, número de páginas parcial e total e o responsável pela elaboração e aprovação do documento.

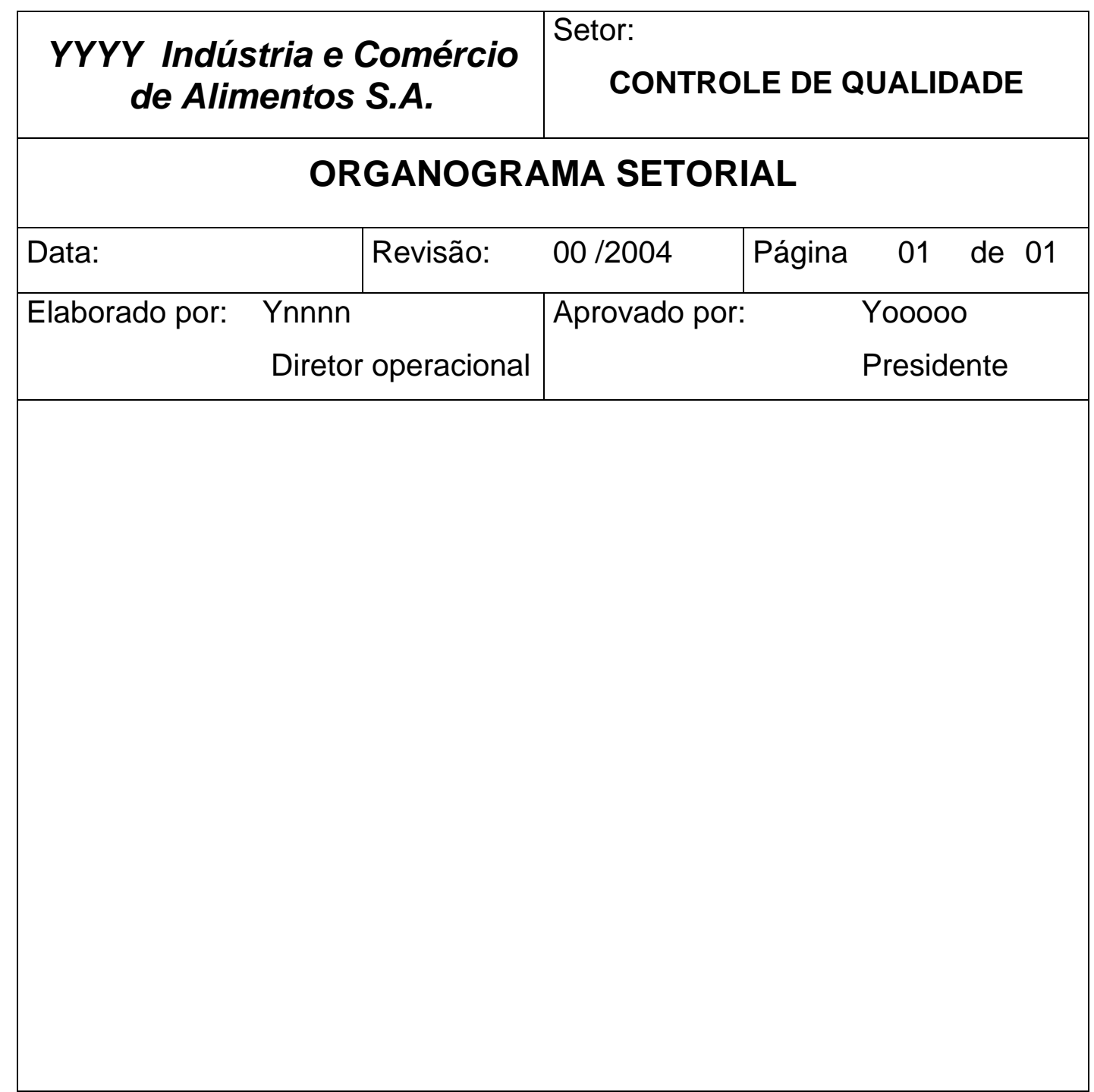

Figura 2 - Estrutura padronizada do organograma setorial 


\subsubsection{Definição funcional}

A sistemática para estabelecer a definição do cargo ocupado pelos colaboradores foi através da elaboração do documento denominado ficha de descrição de cargo, que demonstrava a função do colaborador, os prérequisitos mínimos necessários e as atribuições e responsabilidades da função (Figura 3).

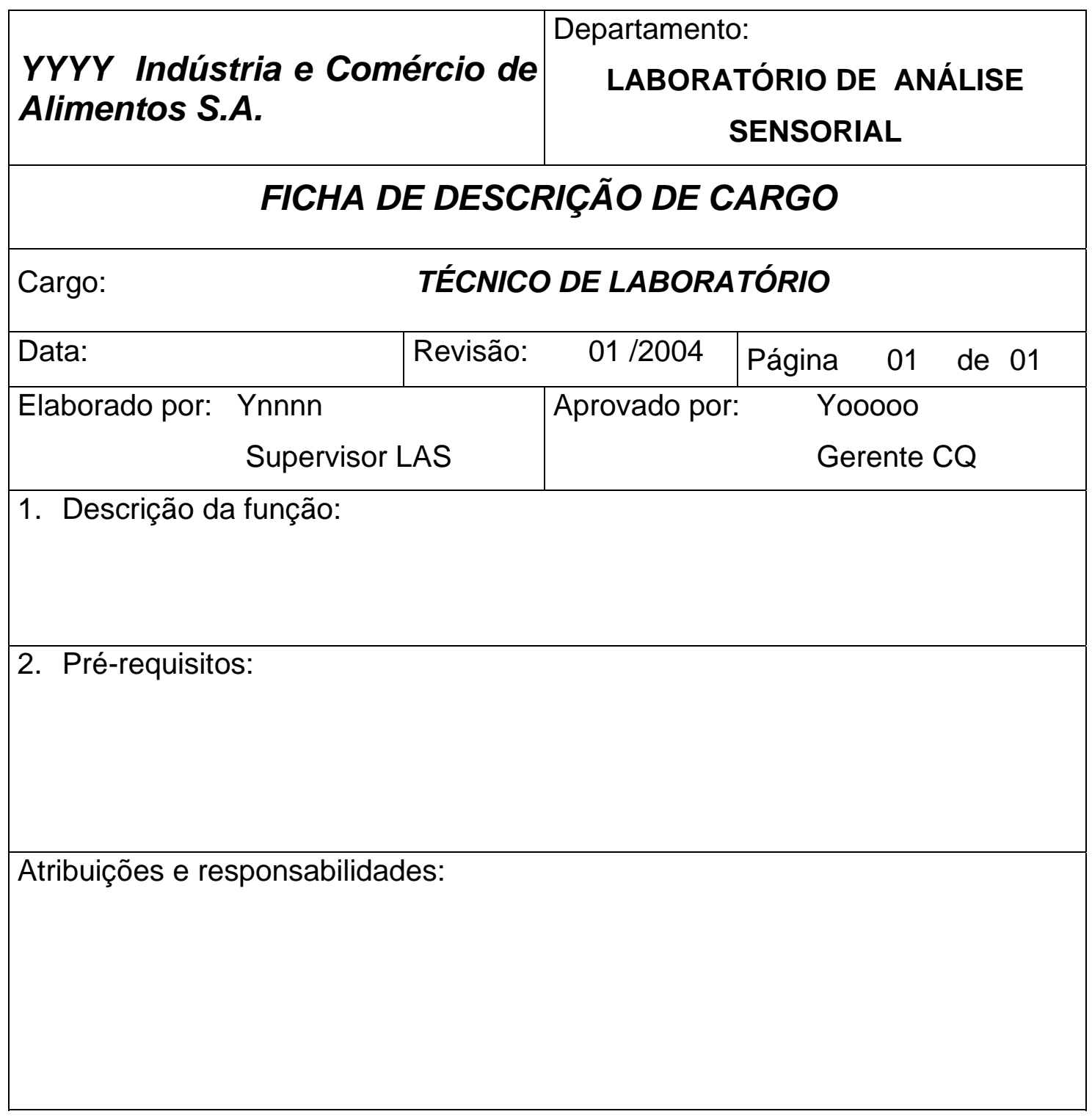

Figura 3 - Documento de descrição de cargo dos colaboradores 
No documento elaborado, a descrição da função foi apresentada de forma sucinta no respectivo campo.

Os pré-requisitos representavam os itens mínimos necessários para ocupar o cargo, como: escolaridade, cursos complementares, experiências profissionais, conhecimentos específicos, características pessoais e perfil de comportamento.

As atribuições e responsabilidades foram descritas em forma de tópicos, contendo as informações das obrigatoriedades do colaborador, descrição das tarefas e as responsabilidades favorecidas pelo cargo.

\subsubsection{Instalações}

Foi estabelecida a sistemática para o levantamento e características das instalações, bem como as propostas de modificações necessárias, objetivando atender os princípios estabelecidos pelo Sistema de Qualidade.

O documento que caracteriza as instalações foi elaborado para registrar os dados adquiridos (Figura 4). 


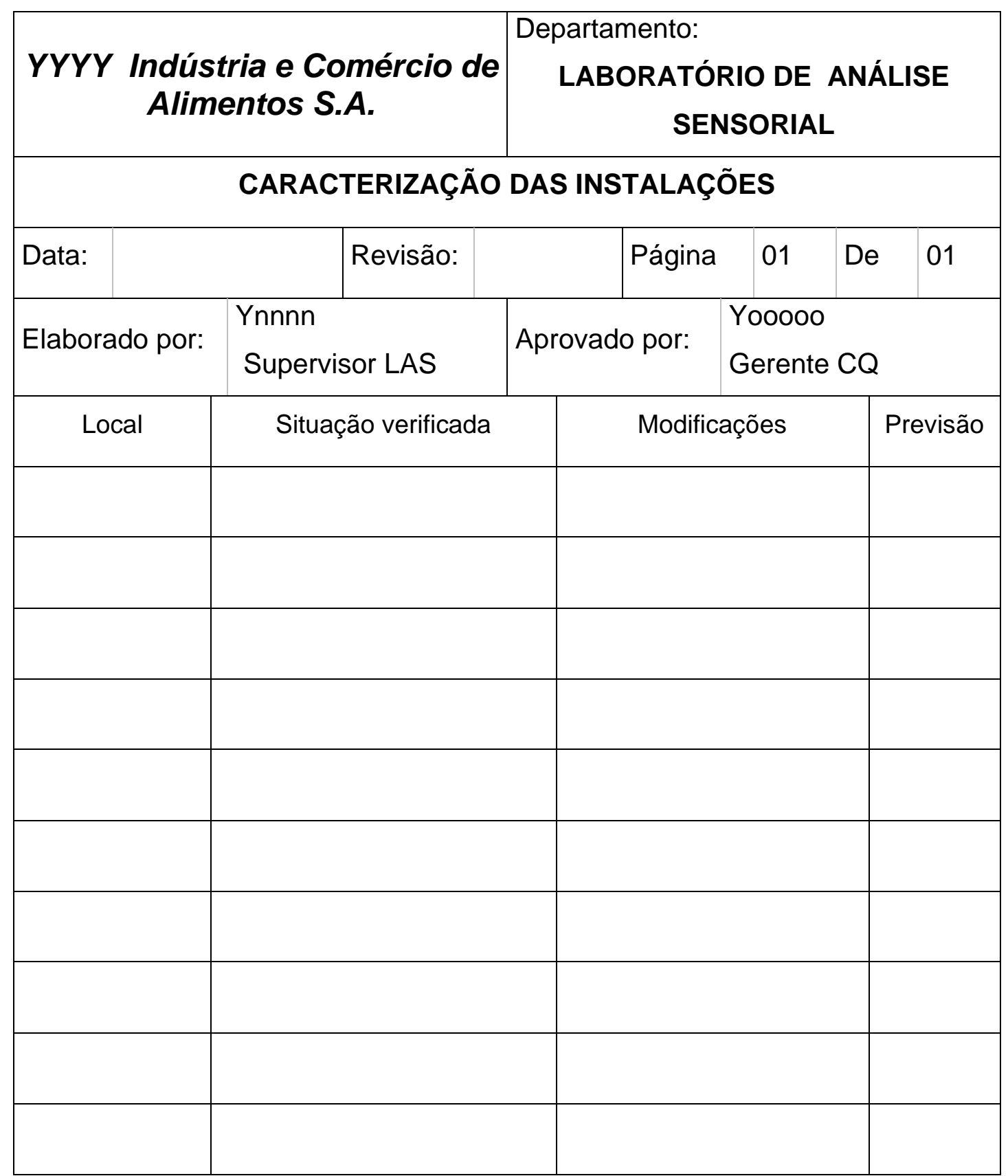

Figura 4 - Documento de caracterização das instalações

No documento de caracterização das instalações foi inserida a indicação do departamento, data da elaboração ou atualização, número da 
revisão vigente, número de páginas parcial e total e o responsável pela elaboração e aprovação do documento. No processo de caracterização foi descrito o local, a situação verificada, as indicações para modificações e a previsão da execução.

\subsubsection{Padronização dos procedimentos}

Os Procedimentos Operacionais Padrão foram elaborados de acordo com a estrutura padronizada e considerados como documentos da qualidade, pois representavam de forma detalhada todas as atividades de rotina do laboratório, servindo de roteiro de trabalho, para que as tarefas fossem executadas sempre da mesma maneira.

Foi desenvolvida e estabelecida a estrutura padrão para redigir os POP's, a qual está apresentada na Figura 5. 


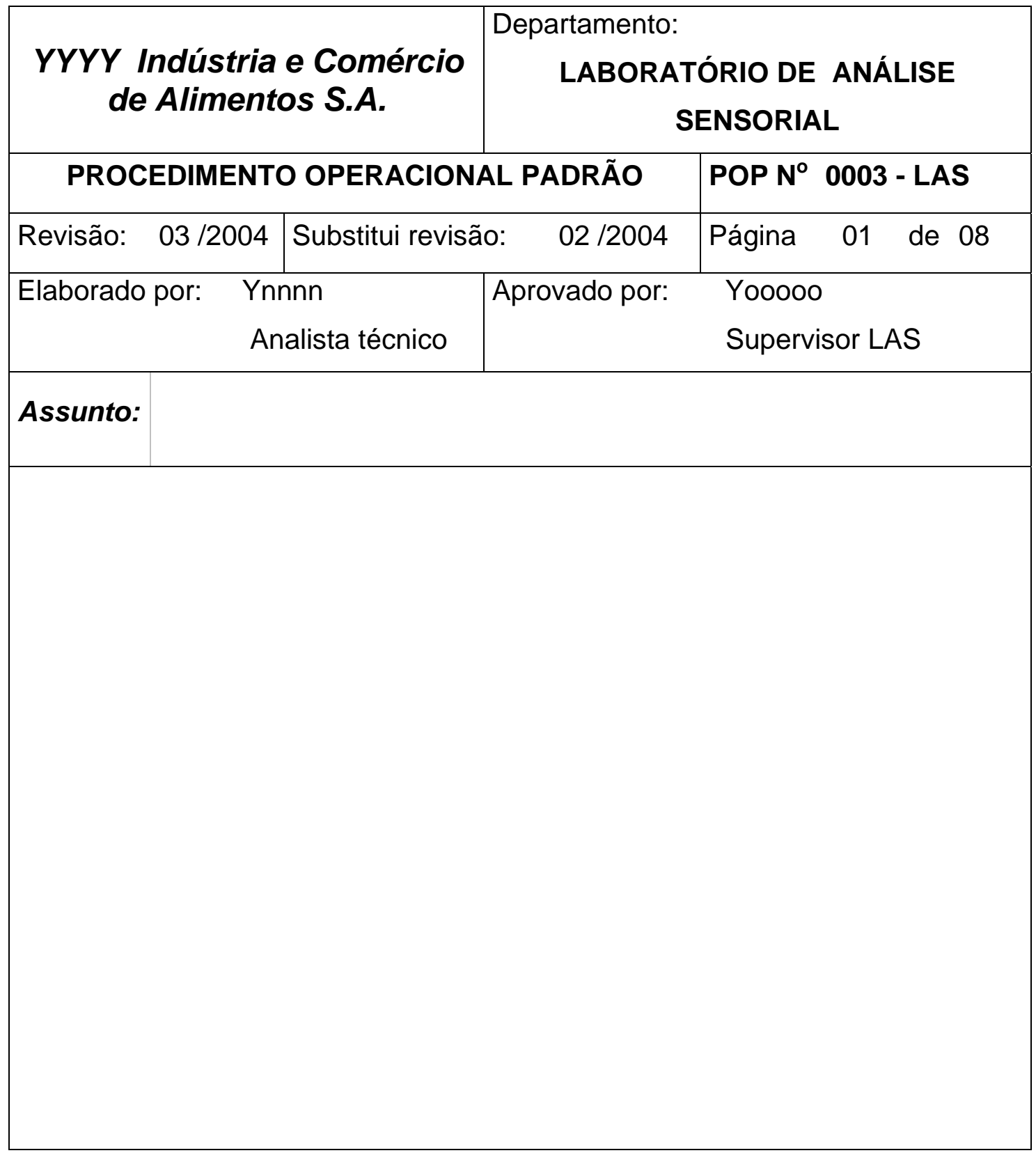

Figura 5 - Estrutura padronizada do POP

A estrutura padronizada apresentou numeração que distinguiu de outros procedimentos, seguida da denominação LAS (Laboratório de Análise Sensorial). Demonstrou o número da revisão do documento, número de páginas, parcial e total e o assunto a que se referiu o procedimento descrito. 
Os procedimentos pertencentes às atividades do laboratório e suas interfaces foram elaborados pelos colaboradores envolvidos com as operações e foram aprovados pelos responsáveis.

Foi estabelecido um critério que definiu as informações necessárias do cabeçalho do POP, que estão apresentadas na Tabela 3.

Tabela 3. Itens necessários para o cabeçalho do POP

\begin{tabular}{cl}
\hline Itens & \multicolumn{1}{c}{ Conteúdo } \\
\hline 1 & Nome da empresa \\
3 & Departamento \\
4 & Descrição do documento \\
5 & Número do documento \\
6 & Súmero da revisão / ano \\
7 & Número de páginas - parcial e total o documento \\
8 & Responsável pela elaboração do documento \\
9 & Responsável pela aprovação do documento \\
10 & Assunto \\
\hline
\end{tabular}

As informações necessárias para o corpo dos Procedimentos Operacionais Padrão foram estabelecidas através da padronização de dois tipos estruturais distintos em função das diversificações das atividades.

A Tabela 4 demonstra as informações necessárias para o corpo do Procedimento Operacionais Padrão - Tipo I, que foram destinadas para descreverem as atividades gerais. 
Tabela 4. Informações necessárias para o corpo do POP - tipo I

\begin{tabular}{cl}
\hline Itens & \multicolumn{1}{c}{ Estrutura } \\
\hline 1 & Objetivo \\
2 & Abrangência \\
3 & Terminologia \\
4 & Procedimento descritivo da atividade \\
5 & Referências \\
6 & Registros e documentos \\
\hline
\end{tabular}

A sistemática definiu que o item objetivo especifica a finalidade e o propósito do procedimento descrito.

$\mathrm{Na}$ abrangência foram mencionados o campo de aplicação, as áreas e atividades contempladas no procedimento.

A terminologia foi relacionada com a definição das siglas e termos técnicos apresentados no documento.

O procedimento descritivo das atividades representou de forma objetiva as etapas para a realização da tarefa, incluindo quando necessárias, as condições especiais de operações e recursos explicativos, o que facilitou o entendimento como, ilustrações, fluxograma e esquematização.

Nas referências foram relacionados os materiais e bibliografia.

Os registros e documentos que fazem parte do Procedimento Operacional Padrão foram inseridos e apresentados como anexos.

As informações necessárias para o corpo do Procedimento Operacionais Padrão - Tipo II foram direcionadas especificamente para as atividades operacionais (Tabela 5). 
Tabela 5. Informações necessárias para o corpo do POP - tipo II

\begin{tabular}{cl}
\hline Itens & \multicolumn{1}{c}{ Estrutura } \\
\hline 1 & Objetivo \\
2 & Equipamentos e materiais \\
3 & Equipamentos de segurança \\
4 & Procedimento descritivo da atividade \\
5 & Considerações \\
6 & Referências \\
7 & Registros e documentos \\
8 & Anexos \\
\hline
\end{tabular}

A sistemática para a descrição dos itens: objetivo; procedimento descritivo da atividade; referências; registros e documentos seguiram os mesmos critérios estabelecidos para o tipo I (Tabela 4).

Os itens, equipamentos e materiais, foram relacionados aos recursos necessários para a realização das tarefas, descritas em forma de listagem, informando o nome e a especificações, quando necessário.

Os equipamentos de segurança, utilizados para garantir a proteção ao indivíduo, na execução das atividades descritas no procedimento, foram listados com a indicação do nome e da especificação.

As considerações mencionaram as informações adicionais complementares.

Os anexos representaram os materiais científicos ou partes. Esses anexos foram utilizados como instrumento de auxílio para o desenvolvimento das atividades.

O critério utilizado para a escolha do padrão, em relação aos dois tipos apresentados, foi estabelecido em função das características das atividades descritas e da necessidade das informações nos procedimentos. 


\subsubsection{Treinamento dos colaboradores}

A metodologia, utilizada para o treinamento dos colaboradores envolvidos nas atividades do laboratório de análise sensorial, foi realizada através de palestras e cursos, para aprimorar os conhecimentos e promover o comprometimento e participação na sistemática de implementação do Sistema de Qualidade.

Os treinamentos dos colaboradores foram estabelecidos a partir da programação de capacitação e treinamento (Figura 6).

Os cursos de capacitação e reciclagem de treinamentos foram planejados e registrados com antecedência, de acordo com as necessidades da função exercida pelo colaborador.

A partir do momento em que os POP's foram elaborados e aprovados, os colaboradores envolvidos nos procedimentos das atividades descritas foram treinados para atuarem de acordo com a sistemática estabelecida. 


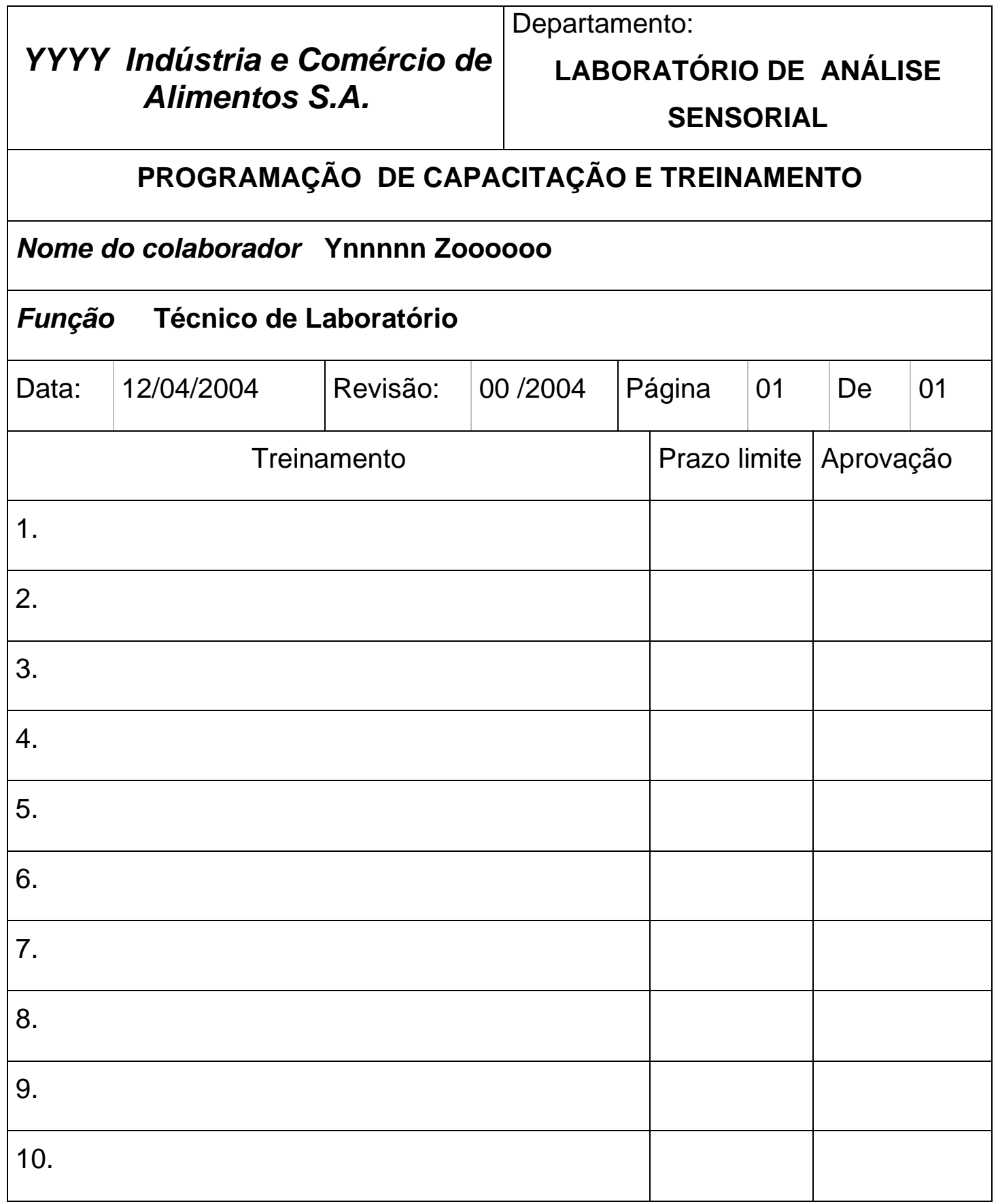

Figura 6 - Programação de capacitação e treinamento

O prazo limite para realização dos treinamentos foi estabelecido em função da disponibilidade e oportunidade do treinamento programado. 
As revisões e o planejamento das programações de treinamentos foram realizados semestralmente, pelo responsável do laboratório em consenso com o colaborador.

A aprovação do treinamento programado foi realizada pelo responsável do departamento ou superior imediato.

Como demonstrativo da capacitação e treinamentos, foi desenvolvida a estrutura padronizada para registrar todos os treinamentos realizados (Figura 7 ). 


\begin{tabular}{|c|c|c|c|c|c|}
\hline $\begin{array}{l}\text { YYYY Indústria e Comércio de } \\
\text { Alimentos S.A. }\end{array}$ & de $\quad \begin{array}{r}\text { Depa } \\
\end{array}$ & \multicolumn{4}{|c|}{$\begin{array}{c}\text { LABORATÓRIO DE ANÁLISE } \\
\text { SENSORIAL }\end{array}$} \\
\hline \multicolumn{6}{|c|}{ DEMONSTRATIVO DE CAPACITAÇÃO E TREINAMENTO } \\
\hline \multicolumn{6}{|c|}{ Nome do colaborador $\quad$ Ynnnnn Zoooooo } \\
\hline Função Técnico de Laboratório & Págil & & 01 & De & 04 \\
\hline Treinamento & Duração & Data & Colaborador & & nsável \\
\hline \multicolumn{6}{|l|}{1.} \\
\hline \multicolumn{6}{|l|}{2.} \\
\hline \multicolumn{6}{|l|}{3.} \\
\hline \multicolumn{6}{|l|}{4.} \\
\hline \multicolumn{6}{|l|}{5.} \\
\hline \multicolumn{6}{|l|}{6.} \\
\hline \multicolumn{6}{|l|}{7.} \\
\hline \multicolumn{6}{|l|}{8.} \\
\hline \multicolumn{6}{|l|}{9.} \\
\hline 10. & & & & & \\
\hline
\end{tabular}

Figura 7 - Demonstrativo de capacitação e treinamento 
Os treinamentos e cursos realizados foram registrados em itens e com as informações complementares, período de duração e data do treinamento.

A confirmação do treinamento realizado foi evidenciada a partir do visto do colaborador que executou o treinamento e do superior responsável. A cópia dos certificados ou dos comprovantes da realização dos cursos ou treinamentos foi anexada junto ao registro.

\subsubsection{Monitoramento e verificação do sistema de qualidade}

Após a implementação do Sistema de Qualidade, foram realizados os processos de monitoramento e verificação, para assegurar que as atividades desenvolvidas no laboratório de análise sensorial se apresentavam em conformidade com os princípios e requisitos estabelecidos.

A equipe de auditores para esta atividade foi composta por duas pessoas, pertencentes ao departamento de garantia de qualidade, que apresentavam qualificação e treinamentos necessários para exercerem a função e que não tinham envolvimento direto com as atividades do laboratório de análise sensorial.

\subsubsection{Programação do monitoramento}

Foi elaborada a sistemática para a programação do monitoramento e verificação do Sistema de Qualidade, através do desenvolvimento da estrutura padrão (Figura 8). 


\begin{tabular}{|c|c|c|c|c|c|c|c|c|}
\hline $\begin{array}{r}\text { YYYY Indús } \\
\text { Alim }\end{array}$ & $\begin{array}{l}\text { e Co } \\
\text { os } S \text {. }\end{array}$ & A. & & $\begin{array}{l}\text { Setor: } \\
\qquad \text { GA }\end{array}$ & RANTI & DE QU & LID & \\
\hline PROG & MAÇÃ & O DE MC & DIT & ORAME & ITO E I & ERIFIC & ÇAO & \\
\hline Data: & & Revisão: & & $/ 2004$ & Página & 01 & de & 01 \\
\hline Elaborado por: & & & & Aprovac & o por: & & & \\
\hline Departamento & Data & & Verifi & icação n & & Auditore & & \\
\hline & & & & & & & & \\
\hline & & & & & & & & \\
\hline & & & & & & & & \\
\hline & & & & & & & & \\
\hline & & & & & & & & \\
\hline & & & & & & & & \\
\hline & & & & & & & & \\
\hline & & & & & & & & \\
\hline & & & & & & & & \\
\hline & & & & & & & & \\
\hline & & & & & & & & \\
\hline
\end{tabular}

Figura 8- Programação de monitoramento e verificação

A programação de monitoramento e verificação compôs em sua estrutura as informações da data e do local que foi monitorado, auditores responsáveis e o número da verificação.

Observou-se também a importância de registrar a data da elaboração, o número da revisão e de páginas parcial e total do documento.

A pessoa que elaborou a programação era pertencente ao departamento de garantia de qualidade e o coordenador foi quem aprovou o documento. 
A primeira verificação ou auditoria foi realizada imediatamente após o término da implementação do sistema, uma segunda verificação foi realizada após três meses e uma terceira auditoria foi realizada após seis meses, conforme foi estabelecido na programação de monitoramento e verificação.

\subsubsection{Elaboração da lista de verificação}

A equipe de auditores elaborou um plano de monitoramento ou lista de verificação, que serviu como instrumento para conduzir o processo de auditoria, pois disponibilizou os itens que foram checados e registrou a condição de conformidade observada.

A estrutura desenvolvida para redigir a lista de verificação, apresentou as informações sobre o local que foi monitorado e data, o número da revisão e a numeração de páginas parcial e total (Figura 9). 


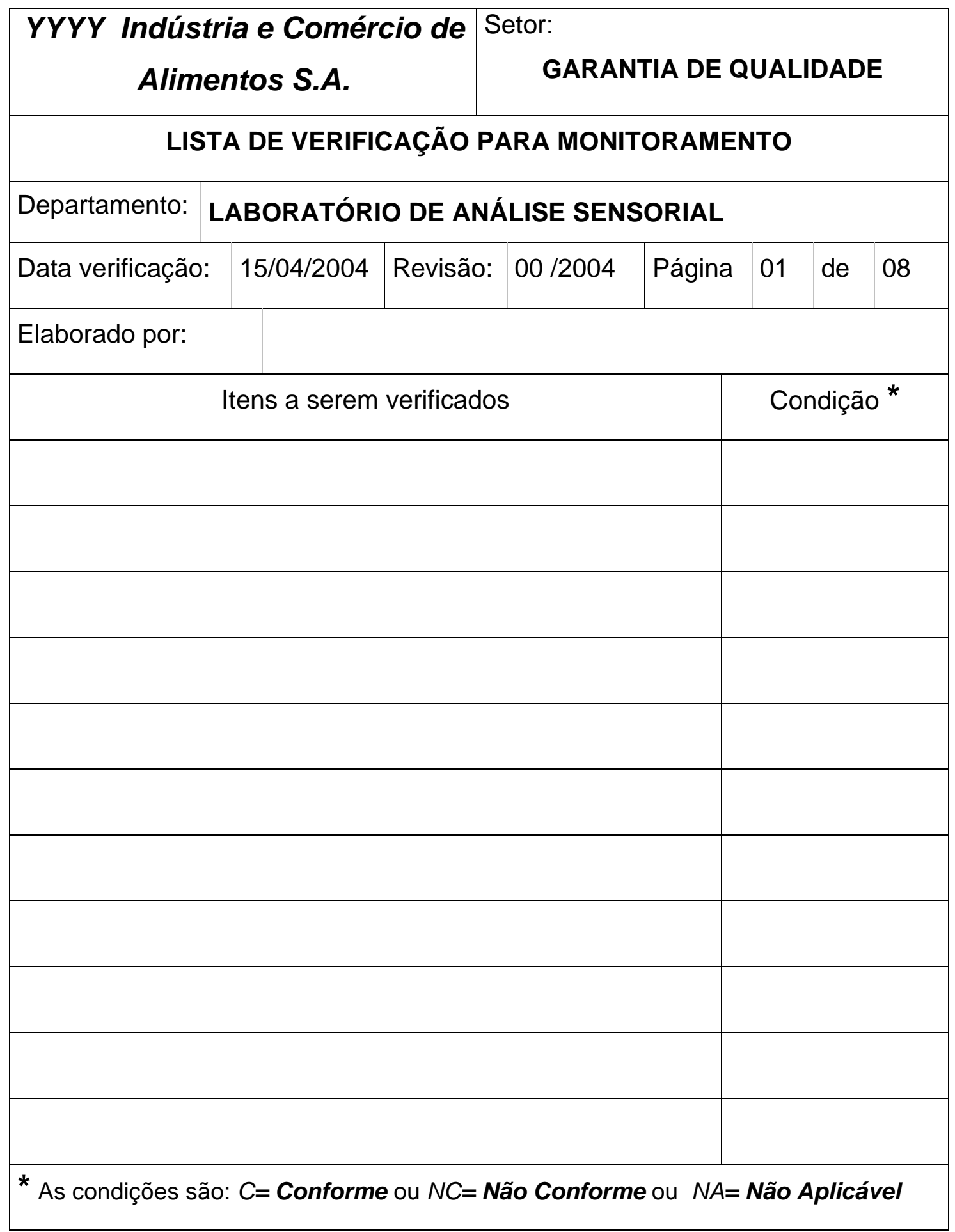

Figura 9 - Lista de verificação para monitoramento 
A lista de verificação (Anexo 1), foi elaborada a partir das diretrizes estabelecidas pelo Sistema de Qualidade baseado nos princípios de Boas Práticas de Laboratório e Boas Práticas de Fabricação, das normas e legislações relacionadas às atividades do escopo e resolução no 275/2003 da ANVISA.

\subsubsection{Registro de não conformidades}

No processo de monitoramento e verificação, as evidências que não se apresentavam de acordo com os princípios do Sistema de Qualidade implementado, foram consideradas como não conformidades.

As não conformidades encontradas foram registradas no documento padronizado conforme Figura 10. 


\begin{tabular}{|c|c|c|c|c|}
\hline $\begin{array}{r}\text { YYYY Indi } \\
\text { de Ali }\end{array}$ & $\begin{array}{l}\text { istria e Comércio } \\
\text { mentos S.A. }\end{array}$ & NÃO CONFOR & ADE $\mathrm{N}^{\circ}$ & 001 \\
\hline Referência: & SISTEMA DE QUALI & DE BASEADO I & BOAS $\mathrm{F}$ & ÁTICAS \\
\hline Departamento & LABORATÓRIO DE & NÁLISE SENSO & & \\
\hline Verificação $n^{0}$ & 0001 & Data: & & \\
\hline Auditor: & Ynnnn & Auditado: & Yoo0oo & \\
\hline Descrição da & não conformidade: & & & \\
\hline Levantamentc & das possíveis caus & & & \\
\hline Causa princip & & & & \\
\hline & Proposta da ação c & etiva: & & \\
\hline & O quê (W): & & & \\
\hline & Por que (W): & & & \\
\hline & Onde (W): & & & \\
\hline & Como $(H)$ : & & & \\
\hline & Quem (W): & & & \\
\hline & Quando (W): & & & \\
\hline & Verificação da eficá & da ação propo & & \\
\hline Auditor: & & Data: & & \\
\hline
\end{tabular}

Figura 10- Registro de não conformidade 
O registro de não conformidades foi desenvolvido com o objetivo de: apresentar as não conformidades encontradas; realizar o levantamento das possíveis causas e identificar a causa principal; elaborar a proposta de ação corretiva; verificar a eficácia da ação corretiva aplicada.

A equipe de auditores foi a responsável pela emissão do documento com a descrição das não conformidades.

Realizou-se trabalho em equipe na área auditada, para o levantamento das possíveis causas e identificação da causa principal, que promoveram as não conformidades, utilizou-se como ferramenta de auxílio, o diagrama de causa e efeito.

Os responsáveis pelo laboratório, apresentaram a proposta da ação corretiva, a partir da causa principal apontada, com a aplicação do método de qualidade 5W1H (What, Why, Where, When, Who, How).

Após aplicação das ações corretivas, a equipe de auditores realizou o fechamento das não conformidades, através da avaliação da eficácia da ação proposta.

\subsubsection{Relatório de monitoramento}

O relatório de auditoria apresentou a relação das não conformidades encontradas, os itens do Sistema de Qualidade verificados e as considerações. Foram demonstradas também, as informações do número da verificação, do departamento monitorado, data, horário, nome dos auditores e dos auditados.

A equipe de auditores foi quem elaborou o relatório, com aprovação do coordenador de qualidade.

O relatório de monitoramento foi desenvolvido de forma padronizada (Figura 11). 


\begin{tabular}{|c|c|c|c|}
\hline \multicolumn{2}{|c|}{$\begin{array}{l}\text { YYYY Indústria e Comércio de } \\
\text { Alimentos S.A. }\end{array}$} & \multicolumn{2}{|c|}{ RELATÓRIO DE MONITORAMENTO } \\
\hline Referência: & \multicolumn{3}{|c|}{$\begin{array}{l}\text { Sistema de Qualidade baseado nas Boas Práticas de } \\
\text { Laboratório e Boas Práticas de Fabricação }\end{array}$} \\
\hline Departamento: & \multicolumn{3}{|c|}{ LABORATÓRIO DE ANÁLISE SENSORIAL } \\
\hline \multicolumn{2}{|c|}{ Verificação nํㅜ 0001} & Pág & $\begin{array}{llll}\text { ina } & 01 & \text { de } & 08\end{array}$ \\
\hline \begin{tabular}{l|l} 
Início: & (data)
\end{tabular} & (horário) & Final: (data) & (horário) \\
\hline \multicolumn{2}{|c|}{$\begin{array}{ll}\text { Equipe auditados: } & \text { Ynnnn } \\
& \text { Vmm }\end{array}$} & \multicolumn{2}{|c|}{$\begin{aligned} \text { Equipe auditores: } & \text { Yooooo } \\
& \text { Xaaaaa }\end{aligned}$} \\
\hline Elaborado : & & Aprovado: & \\
\hline \multicolumn{4}{|c|}{ Não conformidades encontradas: } \\
\hline \multicolumn{4}{|c|}{ Itens verificados: } \\
\hline \multicolumn{4}{|l|}{ Considerações: } \\
\hline
\end{tabular}

Figura 11- Relatório de monitoramento 


\section{RESULTADOS E DISCUSSÃO}

\subsection{Resultados da implementação do sistema de qualidade}

O Sistema de Qualidade foi implementado no laboratório de análise sensorial de uma indústria de alimentos, após sua apresentação e aprovação. A apresentação do Sistema de Qualidade à empresa resultou em uma reunião de aproximadamente 3 horas, com a participação do diretor administrativo, diretor operacional, gerente do controle de qualidade, gerente de processos, gerente de manutenção e projetos, gerente de recursos humanos e gerente de finanças.

A implementação do Sistema de Qualidade foi considerada pertinente, pois apresentava em consonância com um dos objetivos da organização, em promover a melhoria contínua através do aprimoramento do Sistema de Gestão da Qualidade.

A indústria fica localizada na região Sudeste do estado de São Paulo, atua no segmento de produção e comercialização de produtos alimentícios, representa uma produção anual de 28 mil toneladas e é composta por uma equipe de 450 colaboradores.

O organograma do laboratório de análise sensorial foi inserido no organograma geral da indústria de alimentos, conforme representado na Figura 12. 


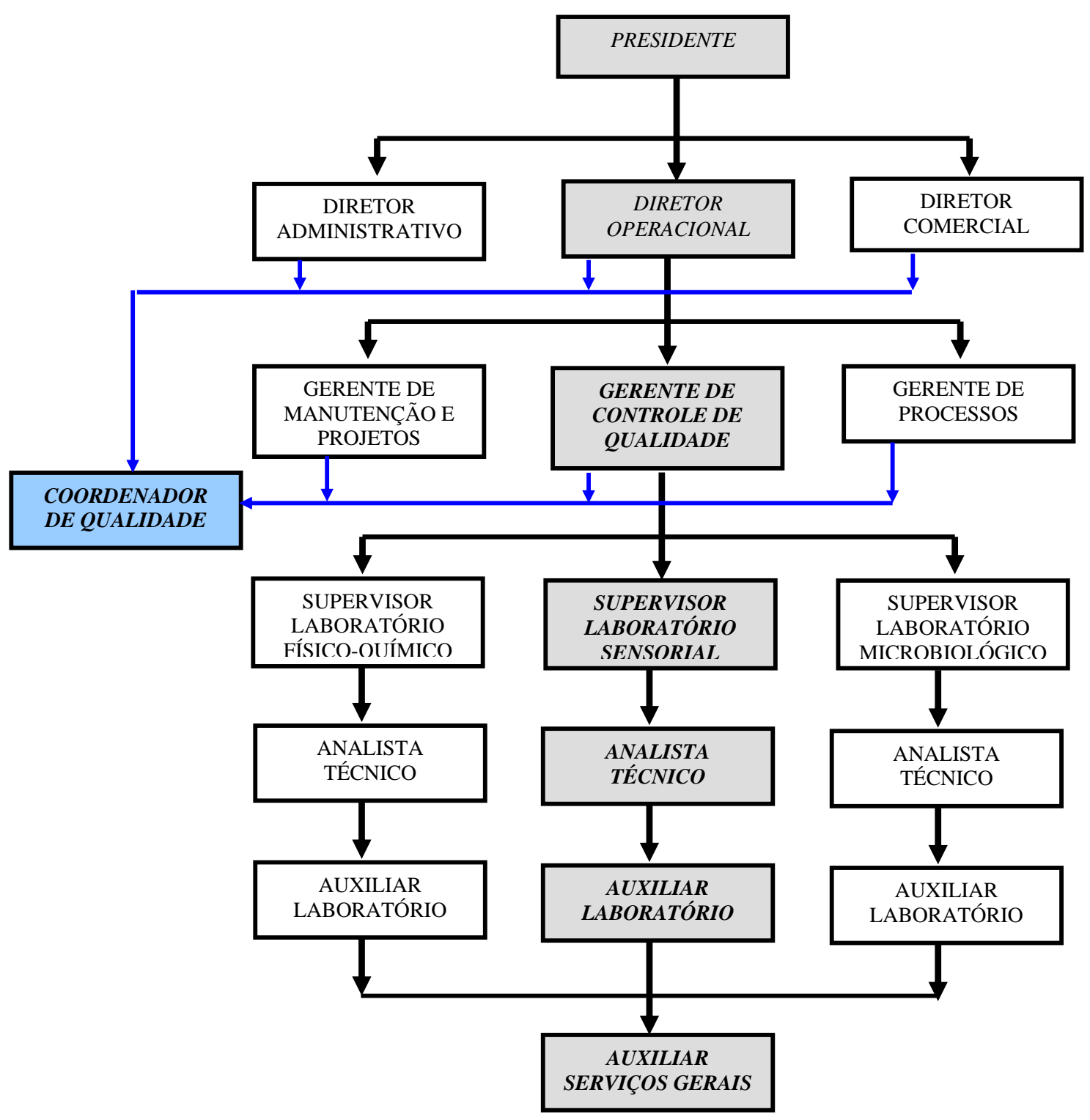

Figura 12 - Organograma do laboratório de análise sensorial 
A equipe de colaboradores que caracterizam o laboratório de análise sensorial é constituída estruturalmente por 6 colaboradores (Tabela 6).

Tabela 6. Equipe de colaboradores do laboratório de análise sensorial

\begin{tabular}{lc}
\hline \multicolumn{1}{c}{ Cargo/ função } & Quantidade pessoas \\
\hline Gerente do Controle de Qualidade & 01 \\
Supervisor do Laboratório de Análise Sensorial & 01 \\
Analista Técnico & 01 \\
Auxiliar de Laboratório & 02 \\
Auxiliar de Serviços Gerais & 01 \\
\hline
\end{tabular}

O gerente do controle de qualidade é o responsável pelos três laboratórios da organização, laboratório físico-químico, laboratório de análise sensorial e laboratório microbiológico.

O supervisor do laboratório de análise sensorial é a pessoa que coordena as atividades desenvolvidas, acompanha o desempenho do pessoal e aprova os relatórios ou certificados de análise.

O analista técnico é o responsável pela execução das análises, desde o planejamento do teste, realização da análise, até a avaliação dos resultados e elaboração do relatório final.

O auxiliar de laboratório é a pessoa que executa as atividades operacionais desenvolvidas no laboratório, conforme estabelecem os Procedimentos Operacionais Padrão.

O auxiliar de serviços gerais tem a função de manter a limpeza e organização da área e das instalações dos laboratórios.

As informações relacionadas às instalações, pessoal e atividades do laboratório de análise sensorial, estão apresentadas na Tabela 7. 
Tabela 7. Caracterização do laboratório de análise sensorial

\begin{tabular}{ll}
\hline \multicolumn{1}{c}{ Itens investigados } & \multicolumn{1}{c}{ Características } \\
\hline Tamanho do laboratório & Área total de $102 \mathrm{~m}^{2}$ \\
Número total de cabines & 6 cabines individuais \\
Quantidade média de análises & $550 /$ mês \\
Total de colaboradores & 6 pessoas \\
Total de provadores & 60 pessoas \\
Finalidades de utilização do & Monitorar qualidade do produto final \\
laboratório & Monitorar qualidade da matéria prima \\
& Qualificar novos fornecedores \\
& Caracterizar novos produtos \\
& Caracterizar novas matérias primas \\
& Selecionar e treinar os provadores \\
& Comparar os produtos fabricados com \\
& produtos concorrentes \\
\hline
\end{tabular}

O laboratório de análise sensorial encontra-se instalado no segundo piso da edificação, é constituído pelas áreas de: preparação da amostra; cabines de degustação; degustação em grupo; armazenamento das amostras; treinamento e reuniões; escritório; sanitários e vestiários; corredores e escadarias.

Os POP's resultantes do processo de implementação do Sistema de Qualidade contemplam as atividades do laboratório de análise sensorial e as que apresentam interface com o escopo (Tabela 8). 
Tabela 8. Procedimento operacional padrão do sistema de qualidade

\begin{tabular}{ll}
\hline \multicolumn{1}{c}{ Atividade } & Departamento \\
\hline Recepção das amostras, identificação, manuseio e & Laboratório \\
armazenamento & sensorial \\
Análise sensorial, preparo das amostras, execução dos & Laboratório \\
testes, análise dos resultados e relatório final & sensorial \\
Seleção e treinamento dos provadores & Laboratório \\
Higiene e limpeza das instalações, equipamentos e & sensorial \\
utensílios & Laboratório \\
Manejo dos resíduos & sensorial \\
Higiene e saúde dos colaboradores & Laboratório \\
Indexação e armazenamento dos documentos e registros & Laboratório \\
Prevenção da saúde dos colaboradores & sensorial \\
Manutenção e calibração dos equipamentos & Laboratório \\
& sensorial \\
\hline & Manutenção \\
\hline & Suprimentos \\
\hline & Processo \\
\hline
\end{tabular}




\subsection{Resultados do processo de monitoramento e verificação}

Os resultados do processo de monitoramento e verificação do Sistema de Qualidade, implementado no laboratório de análise sensorial da indústria de alimentos, estão contemplados, a primeira, segunda e terceira monitoração.

Os resultados do primeiro processo de monitoração do Sistema de Qualidade estão apresentados na Tabela 9.

Tabela 9. Resultados do primeiro processo de monitoração do sistema de qualidade no laboratório de análise sensorial

\begin{tabular}{l|ll}
\hline $\begin{array}{l}\text { No } \\
01\end{array}$ & $\begin{array}{l}\text { Não } \\
\text { conformidade }\end{array}$ & $\begin{array}{l}\text { Faltou a descrição de cargo para o auxiliar de } \\
\text { laboratório, que exerce atividade no laboratório de } \\
\text { análise sensorial }\end{array}$ \\
\hline $\begin{array}{l}\text { Causa } \\
\text { principal }\end{array}$ & Mão de obra: esquecimento da elaboração do documento \\
\hline O quê (W): & Ação corretiva \\
Por que (W): & $\begin{array}{l}\text { Para atualizar a ficha de descrição de cargos dos } \\
\text { colaboradores }\end{array}$ \\
Onde (W): & $\begin{array}{l}\text { Laboratório de análise sensorial } \\
\text { Como (H): }\end{array}$ \\
Elaborar a ficha e encaminhar ao departamento pessoal \\
Quando (W): $\quad$ Gerente do controle de qualidade
\end{tabular}


Tabela 9. Resultados do primeiro processo de monitoração do sistema de qualidade no laboratório de análise sensorial

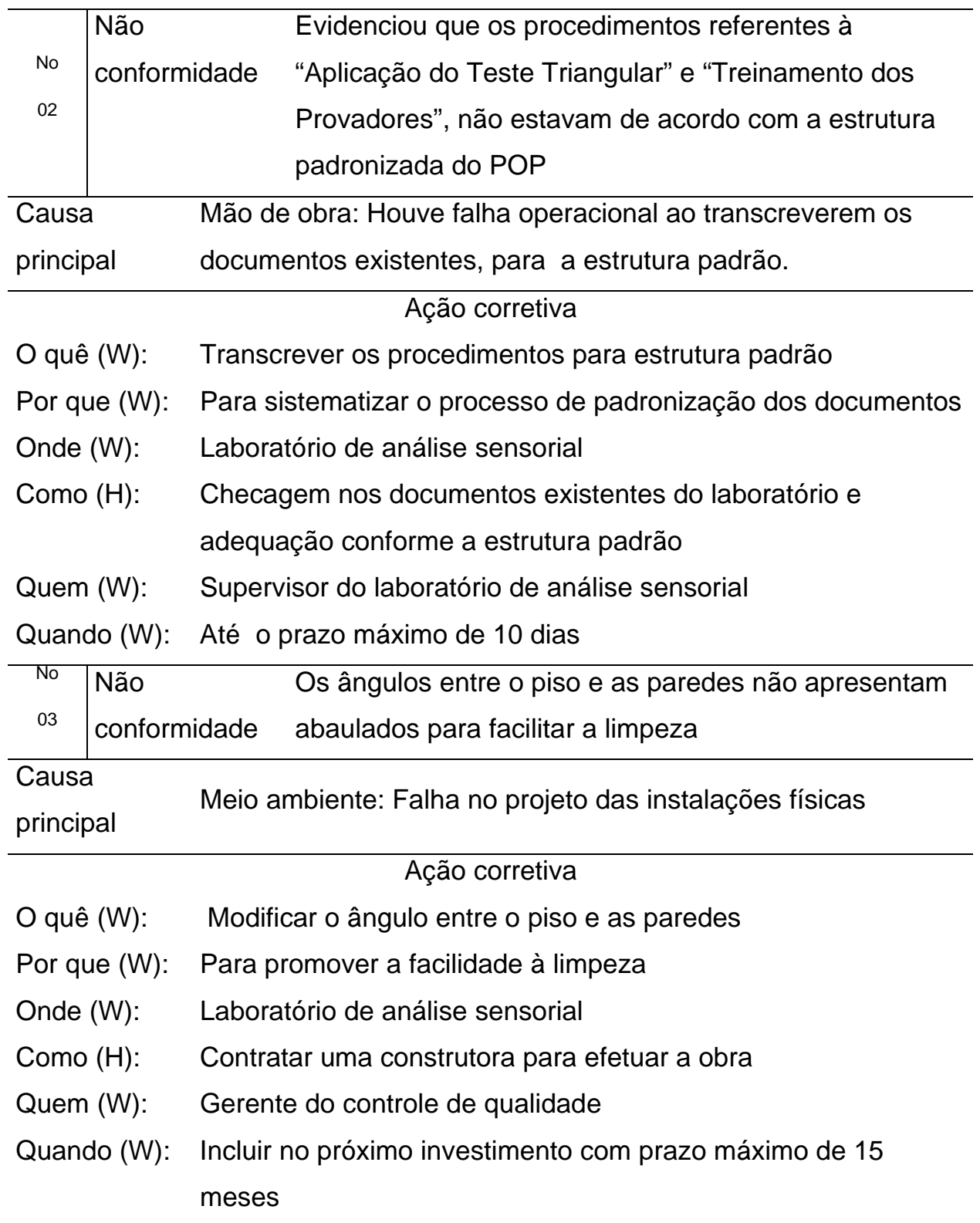


Tabela 9. Resultados do primeiro processo de monitoração do sistema de qualidade no laboratório de análise sensorial

\begin{tabular}{|c|c|c|c|}
\hline $\begin{array}{l}\text { No } \\
04\end{array}$ & $\begin{array}{l}\text { Não } \\
\text { conform }\end{array}$ & idade & $\begin{array}{l}\text { As cabines de degustação não estão providas de } \\
\text { equipamentos que promovam o conforto térmico. }\end{array}$ \\
\hline \multicolumn{2}{|c|}{$\begin{array}{l}\text { Causa } \\
\text { principal }\end{array}$} & \multicolumn{2}{|c|}{$\begin{array}{l}\text { Meio ambiente: Durante o projeto das instalações foi } \\
\text { considerado desnecessário. }\end{array}$} \\
\hline \multicolumn{4}{|r|}{ Ação corretiva } \\
\hline \multicolumn{2}{|c|}{ O quê (W): } & \multicolumn{2}{|c|}{ Instalar os equipamento de ar condicionado } \\
\hline \multicolumn{2}{|c|}{ Por que (W): } & \multicolumn{2}{|c|}{ Favorecer o conforto térmico } \\
\hline \multicolumn{2}{|c|}{ Onde (W): } & \multicolumn{2}{|c|}{ Cabines de degustação do laboratório de análise sensorial } \\
\hline \multicolumn{2}{|c|}{ Como $(H)$ : } & \multicolumn{2}{|c|}{ Contratar empresa especializada } \\
\hline \multicolumn{2}{|c|}{ Quem (W): } & \multicolumn{2}{|c|}{ Gerente do controle de qualidade } \\
\hline \multicolumn{2}{|c|}{ Quando (W): } & \multicolumn{2}{|c|}{$\begin{array}{l}\text { Aquisição no próximo investimento com prazo máximo de seis } \\
\text { meses }\end{array}$} \\
\hline & $\begin{array}{l}\text { Não } \\
\text { conform }\end{array}$ & idade & $\begin{array}{l}\text { Na área que antecede as cabines, não existe lavatório } \\
\text { para lavagem das mãos dos provadores }\end{array}$ \\
\hline \multicolumn{2}{|c|}{$\begin{array}{l}\text { Causa } \\
\text { principal }\end{array}$} & \multicolumn{2}{|c|}{$\begin{array}{l}\text { Meio ambiente: No projeto das instalações não foi considerado } \\
\text { este item. }\end{array}$} \\
\hline \multicolumn{4}{|c|}{ Ação corretiva } \\
\hline \multicolumn{2}{|c|}{ O quê (W): } & \multicolumn{2}{|c|}{ Instalar o lavatório e acessórios } \\
\hline \multicolumn{2}{|c|}{ Por que (W): } & \multicolumn{2}{|c|}{ Fornecer condições de higienização das mãos aos provadores } \\
\hline \multicolumn{2}{|c|}{ Onde $(W)$ : } & \multicolumn{2}{|c|}{ Área que antecede as cabines de degustação } \\
\hline \multicolumn{2}{|c|}{ Como $(H)$ : } & \multicolumn{2}{|c|}{ Adequar a disposição da área } \\
\hline \multicolumn{2}{|c|}{ Quem (W): } & \multicolumn{2}{|c|}{ Gerente do controle de Qualidade } \\
\hline \multicolumn{2}{|c|}{ Quando (W): } & \multicolumn{2}{|c|}{ Incluir no próximo investimento com prazo máximo de um ano } \\
\hline
\end{tabular}


Tabela 9. Resultados do primeiro processo de monitoração do sistema de qualidade no laboratório de análise sensorial

\begin{tabular}{l|ll}
\hline $\begin{array}{c}\text { No } \\
06\end{array}$ & $\begin{array}{l}\text { Não } \\
\text { conformidade }\end{array}$ & $\begin{array}{l}\text { O equipamento "balança semi-analítica", submetido à } \\
\text { manutenção preventiva, não apresentava registro de } \\
\text { comprovação. }\end{array}$ \\
\hline Causa & $\begin{array}{l}\text { Máquinas: Após manutenção preventiva não foi efetuado } \\
\text { principal }\end{array}$ \\
\hline
\end{tabular}

\section{Ação corretiva}

O quê (W): Registrar em documento a atividade de manutenção preventiva

Por que (W): Assegurar o controle do processo de manutenção preventiva

Onde (W): $\quad$ Nos equipamentos do laboratório

Como $(\mathrm{H})$ : $\quad$ Fazer levantamento e providenciar os registros para comprovar as manutenções preventivas dos equipamentos do laboratório.

Quem (W): Responsável pela manutenção dos equipamentos Quando (W): No prazo máximo de 2 meses

\begin{tabular}{|c|c|c|c|}
\hline $\begin{array}{l}\text { No } \\
07\end{array}$ & $\begin{array}{l}\text { Não } \\
\text { conforr }\end{array}$ & nidade & $\begin{array}{l}\text { Não foram evidenciados os documentos de } \\
\text { comprovação da calibração para o instrumento de } \\
\text { medição, "refratômetro". }\end{array}$ \\
\hline \multicolumn{2}{|c|}{$\begin{array}{l}\text { Causa } \\
\text { principal }\end{array}$} & \multicolumn{2}{|c|}{$\begin{array}{l}\text { Máquinas: Após processo de calibração não foi providenciada } \\
\text { a documentação. }\end{array}$} \\
\hline \multicolumn{4}{|r|}{ Ação corretiva } \\
\hline \multicolumn{2}{|c|}{ O quê (W): } & \multicolumn{2}{|c|}{ Providenciar documentação } \\
\hline \multicolumn{2}{|c|}{ Por que $(W)$ : } & \multicolumn{2}{|c|}{ Comprovar a calibração } \\
\hline \multicolumn{2}{|c|}{ Onde (W): } & \multicolumn{2}{|c|}{ Nos equipamentos e instrumentos do laboratório } \\
\hline \multicolumn{2}{|c|}{ Como $(H)$ : } & \multicolumn{2}{|c|}{$\begin{array}{l}\text { Requisitar ao fornecedor do serviço de calibração dos } \\
\text { equipamentos e instrumentos }\end{array}$} \\
\hline \multicolumn{2}{|c|}{ Quem (W): } & \multicolumn{2}{|c|}{ Supervisor de manutenção } \\
\hline \multicolumn{2}{|c|}{ Quando (W): } & \multicolumn{2}{|c|}{ Prazo máximo de 2 meses } \\
\hline
\end{tabular}


Tabela 9. Resultados do primeiro processo de monitoração do sistema de qualidade no laboratório de análise sensorial

\begin{tabular}{|c|c|c|c|}
\hline 08 & $\begin{array}{l}\text { Não } \\
\text { conforn }\end{array}$ & nidade & $\begin{array}{l}\text { Na ficha de identificação das amostras dispostas à } \\
\text { análise faltou completar a informação de lote/data }\end{array}$ \\
\hline \multicolumn{2}{|c|}{$\begin{array}{l}\text { Causa } \\
\text { principal }\end{array}$} & \multicolumn{2}{|c|}{ Matéria prima: Esquecimento ao anotar as informações } \\
\hline \multicolumn{4}{|r|}{ Ação corretiva } \\
\hline \multicolumn{2}{|c|}{ O quê (W): } & \multicolumn{2}{|c|}{ Registrar as informações } \\
\hline \multicolumn{2}{|c|}{ Por que (W): } & \multicolumn{2}{|c|}{ Fornecer dados completos das amostras } \\
\hline \multicolumn{2}{|c|}{ Onde (W): } & \multicolumn{2}{|c|}{ Na ficha de identificação das amostras } \\
\hline \multicolumn{2}{|c|}{ Como $(H)$ : } & \multicolumn{2}{|c|}{$\begin{array}{l}\text { Solicitar ao fornecedor das amostras que informe no campo da } \\
\text { ficha esta informação }\end{array}$} \\
\hline \multirow{2}{*}{\multicolumn{2}{|c|}{$\begin{array}{l}\text { Quem }(W) \text { : } \\
\text { Quando (W): }\end{array}$}} & \multirow{2}{*}{\multicolumn{2}{|c|}{$\begin{array}{l}\text { Coordenador do laboratório de análise sensorial } \\
\text { Imediato e para todas as amostras que chegarem ao } \\
\text { laboratório }\end{array}$}} \\
\hline & & & \\
\hline $\begin{array}{l}\text { No } \\
09\end{array}$ & $\begin{array}{l}\text { Não } \\
\text { conforn }\end{array}$ & nidade & $\begin{array}{l}\text { Evidenciou que manipulador das amostras apresentava } \\
\text { com unhas compridas, esmalte e relógio. }\end{array}$ \\
\hline \multicolumn{2}{|c|}{$\begin{array}{l}\text { Causa } \\
\text { principal }\end{array}$} & \multicolumn{2}{|c|}{$\begin{array}{l}\text { Mão de obra: Colaborador não cumpriu os procedimentos } \\
\text { estabelecidos }\end{array}$} \\
\hline
\end{tabular}

\section{Ação corretiva}

O quê (W): Orientar sobre o comportamento das boas práticas

Por que (W): Garantir a atuação das boas praticas no laboratório sensorial

Onde (W): $\quad \mathrm{Na}$ área de manipulação do laboratório

Como $(\mathrm{H})$ : Orientar o colaborador e realizar reciclagem de treinamento sobre as práticas de higiene

Quem (W): Supervisor do laboratório de análise sensorial

Quando (W): Agendar treinamento para todos os manipuladores no prazo de uma semana 
Tabela 9. Resultados do primeiro processo de monitoração do sistema de qualidade no laboratório de análise sensorial

\begin{tabular}{l|ll} 
No & Não & Não foi evidenciada a programação de capacitação dos \\
10 & conformidade & provadores
\end{tabular}

\begin{tabular}{l|l}
\hline $\begin{array}{l}\text { Causa } \\
\text { principal }\end{array}$ & $\begin{array}{l}\text { Medida: Esquecimento da elaboração do documento de } \\
\text { programação de treinamento e capacitação }\end{array}$ \\
\hline & Ação corretiva
\end{tabular}

O quê (W): Providenciar o documento de programação de treinamento

Por que (W): Garantir a sistemática para que os degustadores sejam treinados, quando necessário

Onde (W): Laboratório de análise sensorial

Como $(H)$ : $\quad$ Registrar em documento padronizado os próximos treinamentos para degustadores

Quem (W) Supervisor do laboratório de análise sensorial

Quando (W) Prazo máximo de uma semana

\begin{tabular}{l|ll}
\hline $\begin{array}{c}\text { No } \\
11\end{array}$ & $\begin{array}{l}\text { Não } \\
\text { conformidade }\end{array}$ & $\begin{array}{l}\text { Não foi verificado registro sobre as atividades de } \\
\text { controle de pragas e vetores }\end{array}$ \\
\hline $\begin{array}{l}\text { Causa } \\
\text { principal }\end{array}$ & Método: Esqueceu de elaborar o registrado de monitoramento \\
\hline & \multicolumn{1}{c}{ Ação corretiva } \\
O quê (W): & Elaborar o registro de monitoramento \\
Por que (W): & Garantir a atividade de controle de praga \\
Onde (W): & Laboratório de análise sensorial \\
Como (H): & $\begin{array}{l}\text { Registrar em documento padronizado todo o monitoramento } \\
\text { sobre as atividades de controle de pragas }\end{array}$ \\
Quem (W): & $\begin{array}{l}\text { Supervisor do laboratório de análise sensorial } \\
\text { Quando (W): }\end{array}$ & Prazo máximo de 3 meses
\end{tabular}


Os resultados do segundo processo de monitoração do Sistema de Qualidade estão apresentados na Tabela 10.

Tabela 10. Resultados do segundo processo de monitoração do sistema de qualidade no laboratório de análise sensorial

\begin{tabular}{|c|c|c|}
\hline No & $\begin{array}{l}\text { Não } \\
\text { conformi }\end{array}$ & $\begin{array}{l}\text { Evidenciou que no documento de treinamento dos } \\
\text { colaboradores, auxiliar de laboratório, não estavam } \\
\text { registrados os quatro últimos treinamentos. }\end{array}$ \\
\hline \multirow{2}{*}{\multicolumn{2}{|c|}{$\begin{array}{l}\text { Causa } \\
\text { principal }\end{array}$}} & Mão de obra: Esqueceu de atualizar os documentos \\
\hline & & Ação corretiva \\
\hline \multicolumn{2}{|c|}{ O quê (W): } & Registrar os treinamentos realizados \\
\hline \multicolumn{2}{|c|}{ Por que (W): } & Para evidenciar e comprovar os treinamentos \\
\hline \multicolumn{2}{|c|}{ Onde $(W)$ : } & No registro de demonstrativo de capacitação e treinamento \\
\hline \multicolumn{2}{|c|}{ Como $(H)$ : } & Registrar os treinamentos e providenciar a comprovação \\
\hline \multicolumn{2}{|c|}{ Quem (W): } & Supervisor do laboratório de análise sensorial \\
\hline \multicolumn{2}{|c|}{ Quando (W): } & Até o prazo máximo de 10 dias \\
\hline $\begin{array}{l}\text { No } \\
02\end{array}$ & $\begin{array}{l}\text { Não } \\
\text { conformi }\end{array}$ & $\begin{array}{ll} & \text { Foi verificado nos documentos que operação de } \\
\text { dade } & \text { calibração da balança analítica estava desatualizado }\end{array}$ \\
\hline \multicolumn{2}{|c|}{$\begin{array}{l}\text { Causa } \\
\text { principal }\end{array}$} & $\begin{array}{l}\text { Máquina: Não foi cumprido o prazo estabelecido da } \\
\text { programação, para efetuar a calibração }\end{array}$ \\
\hline \multicolumn{3}{|r|}{ Ação corretiva } \\
\hline \multicolumn{2}{|c|}{ O quê (W): } & Atualizar o processo de calibração \\
\hline \multicolumn{2}{|c|}{ Por que (W): } & Para promover a confiabilidade do instrumento \\
\hline \multicolumn{2}{|c|}{ Onde (W): } & Balança analítica \\
\hline \multicolumn{2}{|c|}{ Como $(H)$ : } & $\begin{array}{l}\text { Providenciar calibração e promover sistemática de checagem } \\
\text { para todos os instrumentos e equipamentos }\end{array}$ \\
\hline \multicolumn{2}{|c|}{ Quem (W): } & Supervisor do departamento de manutenção \\
\hline \multicolumn{2}{|c|}{ Quando (W): } & Até o prazo máximo de 15 dias \\
\hline
\end{tabular}


Tabela 10. Resultados do segundo processo de monitoração do sistema de qualidade no laboratório de análise sensorial

\begin{tabular}{l|ll}
\hline $\begin{array}{c}\text { No } \\
03\end{array}$ & $\begin{array}{l}\text { Não } \\
\text { conformidade }\end{array}$ & $\begin{array}{l}\text { Evidenciou que no processo de recepção de amostra, um } \\
\text { material perecível não especificava a recomendação de } \\
\text { armazenamento sob refrigeração. }\end{array}$ \\
\hline $\begin{array}{l}\text { Causa } \\
\text { principal }\end{array}$ & Matéria prima: Esqueceu de anotar a recomendação de refrigeração
\end{tabular}

$$
\text { Ação corretiva }
$$

O quê (W): Providenciar registro de recomendação de refrigeração

Por que (W): Para garantir a segurança do produto

Onde (W): $\quad$ Na amostra perecível

Como $(\mathrm{H})$ : Solicitar ao fornecedor das amostras que informe a recomendação de refrigeração.

Quem (W): Supervisor do laboratório de análise sensorial

Quando (W): Imediato, para todas as amostras que necessitam de condições especiais para armazenamento

\begin{tabular}{l|ll}
\hline $\begin{array}{l}\text { No } \\
04\end{array}$ & $\begin{array}{l}\text { Não } \\
\text { conformidade }\end{array}$ & $\begin{array}{l}\text { Evidenciou no registro do laboratório, o preenchimento } \\
\text { incompleto sem as informações: data e horário da entrada da } \\
\text { amostra. }\end{array}$ \\
\hline $\begin{array}{l}\text { Causa } \\
\text { principal }\end{array}$ & Método: Esqueceu de registrar as informações \\
\hline
\end{tabular}

O quê (W): Providenciar o registro das informações

Por que (W): Garantir informações padronizadas das amostras

Onde (W): Registro de análise do laboratório de análise sensorial

Como $(H)$ : Providenciar o registro, e programar treinamento aos colaboradores

quanto aos procedimentos operacionais

Quem (W): Supervisor do laboratório de análise sensorial

Quando $(W)$ : Prazo máximo de uma semana 
Tabela 10. Resultados do segundo processo de monitoração do sistema de qualidade no laboratório de análise sensorial

\begin{tabular}{c|ll}
\hline $\begin{array}{l}\text { No } \\
05\end{array}$ & $\begin{array}{l}\text { Não } \\
\text { conformidade }\end{array}$ & $\begin{array}{l}\text { Verificado no documento de programação de treinamento e } \\
\text { capacitação do analista técnico, que o último treinamento } \\
\text { programado não foi cumprido }\end{array}$ \\
\hline $\begin{array}{l}\text { Causa } \\
\text { principal }\end{array}$ & Mão de obra:
\end{tabular}

\section{Ação corretiva}

O quê (W): Avaliar programação de treinamento

Por que (W): Para verificar a viabilidade dos treinamentos programados

Onde (W): Registro de programação de treinamento

Como $(\mathrm{H})$ : Realizar uma análise critica da programação, com relação aos prazos estabelecidos, para dar condições para o cumprimento do cronograma

Quem (W): Gerente do controle de qualidade

Quando (W): No prazo máximo de 30 dias

\begin{tabular}{l|ll}
\hline No & $\begin{array}{l}\text { Não } \\
06\end{array}$ & $\begin{array}{l}\text { Evidenciou na área de manipulação, colaborador não usando a } \\
\text { couca protetora }\end{array}$ \\
\hline Causa & Mão de obra: Colaborador não cumpriu os procedimentos estabelecidos \\
principal
\end{tabular}

\section{Ação corretiva}

O quê (W): Providenciar o comportamento das boas práticas

Por que (W); Garantir as ações de boas práticas no laboratório sensorial

Onde (W): $\quad$ Na área de manipulação do laboratório

Como $(\mathrm{H})$ : Exigir atitude e reforçar na conscientização e treinamento sobre os procedimentos

Quem (W): $\quad$ Supervisor do laboratório de análise sensorial

Quando (W): Imediata e programar treinamento, prazo máximo de uma semana 
Tabela 10. Resultados do segundo processo de monitoração do sistema de qualidade no laboratório de análise sensorial

\begin{tabular}{|c|c|c|}
\hline $\begin{array}{l}\text { No } \\
07\end{array}$ & $\begin{array}{l}\text { Não } \\
\text { conformi }\end{array}$ & $\begin{array}{l}\text { Foi verificado que o POP utilizado, referente a atividade de } \\
\text { idade higiene e sanitização dos equipamentos não correspondia a } \\
\text { revisão atualizada. }\end{array}$ \\
\hline \multicolumn{2}{|c|}{$\begin{array}{l}\text { Causa } \\
\text { principal }\end{array}$} & Medidas: A revisão atualizada do documento não foi substituída \\
\hline \multicolumn{3}{|c|}{ Ação corretiva } \\
\hline \multicolumn{2}{|c|}{ O quê (W): } & Providenciar substituição da revisão atualizada \\
\hline \multicolumn{2}{|c|}{ Por que (W): } & Manter procedimentos atualizados e garantir a validez da revisão \\
\hline \multicolumn{2}{|c|}{ Onde (W): } & Laboratório de análise sensorial \\
\hline \multicolumn{2}{|c|}{ Como $(H)$ : } & Executar a substituição e treinamento aos colaboradores envolvidos \\
\hline \multicolumn{2}{|c|}{ Quem (W): } & Supervisor do laboratório \\
\hline \multicolumn{2}{|c|}{ Quando (W): } & No prazo máximo de uma semana \\
\hline No & $\begin{array}{l}\text { Não } \\
\text { conformi }\end{array}$ & $\begin{array}{l}\text { Foi evidenciado que no registro de não conformidade } \mathrm{n}^{0} 02 \text {, da } \\
\text { idade última auditoria, não foi verificado a eficácia da ação proposta }\end{array}$ \\
\hline \multicolumn{2}{|c|}{$\begin{array}{l}\text { Causa } \\
\text { principal }\end{array}$} & $\begin{array}{l}\text { Método: Falha no fechamento do registro de não conformidade, do } \\
\text { processo de monitoração }\end{array}$ \\
\hline \multicolumn{3}{|r|}{ Ação corretiva } \\
\hline \multicolumn{2}{|c|}{ O quê (W): } & Providenciar a verificação da eficácia \\
\hline \multicolumn{2}{|c|}{ Por que (W): } & Para concluir e atualizar os registros \\
\hline \multicolumn{2}{|c|}{ Onde (W): } & No registro de não conformidade $\mathrm{n}^{\circ} 02$, da última auditoria \\
\hline \multicolumn{2}{|c|}{ Como $(\mathrm{H})$ : } & Checar a eficácia da ação implementada, e relatar no documento \\
\hline \multicolumn{2}{|c|}{ Quem (W): } & Auditores responsáveis pela última auditoria \\
\hline \multicolumn{2}{|c|}{ Quando (W): } & No prazo máximo de uma semana \\
\hline
\end{tabular}


Os resultados do terceiro processo de monitoração do Sistema de Qualidade estão apresentados na Tabela 11.

Tabela 11. Resultados do terceiro processo de monitoração do sistema de qualidade no laboratório de análise sensorial

\begin{tabular}{l|ll}
\hline $\begin{array}{l}\text { No } \\
01\end{array}$ & $\begin{array}{l}\text { Não } \\
\text { conformidade }\end{array}$ & $\begin{array}{l}\text { Verificou no registro de treinamento do gerente de } \\
\text { controle de qualidade a não comprovação do último } \\
\text { treinamento realizado. }\end{array}$ \\
\hline Causa & $\begin{array}{r}\text { Materiais: Não foi emitido o certificado de comprovação do } \\
\text { principal }\end{array}$ \\
\hline
\end{tabular}

Ação corretiva

O quê (W): Providenciar comprovante

Por que (W): Para evidenciar e comprovar o treinamento realizado

Onde (W): $\quad$ No registro de demonstrativo de capacitação e treinamento

Como $(\mathrm{H})$ : Solicitar o certificado, da empresa que ministrou o curso

Quem (W): Supervisor do laboratório de análise sensorial

Quando $(W)$ : Até o prazo máximo de 15 dias

\begin{tabular}{c|ll}
\hline No & Não & $\begin{array}{l}\text { Evidenciou colaborador do laboratório estava } \\
\text { manuseando os produtos sem uso do jaleco protetor }\end{array}$ \\
\hline $\begin{array}{l}\text { Causa } \\
\text { principal }\end{array}$ & Mão de obra: Colaborador esqueceu de usar o jaleco protetor \\
\hline
\end{tabular}

Ação corretiva

O quê (W): Providenciar a colocação do jaleco

Por que (W): Cumprir os procedimentos estabelecidos

Onde (W): No laboratório de análise sensorial

Como $(\mathrm{H})$ : $\quad$ Exigir o cumprimento dos procedimentos e conscientizar o

colaborador sobre a atitude correta.

Quem (W): Supervisor do laboratório

Quando (W): Imediato e prazo máximo de 2 dias 
Tabela 11. Resultados do terceiro processo de monitoração do sistema de qualidade no laboratório de análise sensorial

\begin{tabular}{l|ll}
\hline No & $\begin{array}{l}\text { Não } \\
\text { conformidade }\end{array}$ & $\begin{array}{l}\text { Verificou a presença de material de limpeza e } \\
\text { higienização sem a ficha técnica com dados de } \\
\text { segurança }\end{array}$ \\
\hline $\begin{array}{l}\text { Causa } \\
\text { principal }\end{array}$ & Materiais: Perda da ficha técnica durante atividade de operação
\end{tabular}

\section{Ação corretiva}

O quê $(W)$ : Providenciar a ficha técnica para o material

Por que (W): Promover a segurança dos materiais utilizados

Onde (W): $\quad$ No laboratório de análise sensorial

Como $(\mathrm{H})$ : Requisitar nova ficha para o fornecedor do material

Quem (W): Supervisor do laboratório de análise sensorial

Quando (W): Prazo máximo de 20 dias

\begin{tabular}{|c|c|c|c|}
\hline $\begin{array}{l}\text { No } \\
04\end{array}$ & $\begin{array}{l}\text { Não } \\
\text { conforn }\end{array}$ & idade & $\begin{array}{l}\text { Verificou na programação de intervenções para o } \\
\text { controle de pragas e vetores, que não foi cumprido a } \\
\text { data programada }\end{array}$ \\
\hline \multirow{2}{*}{\multicolumn{2}{|c|}{$\begin{array}{l}\text { Causa } \\
\text { principal }\end{array}$}} & \multicolumn{2}{|c|}{$\begin{array}{l}\text { Houve adiantamento da execução da intervenção, e não } \\
\text { realizou alteração do registro }\end{array}$} \\
\hline & & \multicolumn{2}{|r|}{ Ação corretiva } \\
\hline \multicolumn{2}{|c|}{ O quê (W): } & \multicolumn{2}{|c|}{ Alterar a programação das intervenções } \\
\hline \multicolumn{2}{|c|}{ Por que (W): } & \multicolumn{2}{|c|}{ Atualizar o documento } \\
\hline \multicolumn{2}{|c|}{ Onde (W): } & \multicolumn{2}{|c|}{ No laboratório de análise sensorial } \\
\hline \multicolumn{2}{|c|}{ Como $(H)$ : } & \multicolumn{2}{|c|}{$\begin{array}{l}\text { Rever a programação e atualizar as datas conforme } \\
\text { modificação }\end{array}$} \\
\hline \multicolumn{2}{|c|}{ Quem (W): } & \multicolumn{2}{|c|}{ Gerente do controle de qualidade } \\
\hline \multicolumn{2}{|c|}{ Quando (W): } & \multicolumn{2}{|c|}{ Prazo máximo de 15 dias } \\
\hline
\end{tabular}


Observando os resultados das monitorações, pode-se verificar que na primeira auditoria foram apontadas onze não conformidades, em função do Sistema de Qualidade estar em sua fase inicial, apresentando nuances de fragilidade que requerem tomadas de ações para promover a estabilização.

Na segunda verificação, realizada após três meses, houve uma redução para oito do número de não conformidades, demonstrando que ocorreu um processo de melhoria na funcionalidade do Sistema de Qualidade.

$\mathrm{Na}$ terceira auditoria, que foi realizada após seis meses, observou-se a redução para quatro o número de não conformidades, demonstrando que o laboratório de análise sensorial desenvolveu suas atividades, de maneira a aprimorar o cumprimento dos princípios estabelecidos pelo Sistema de Qualidade implementado.

A representação gráfica do perfil dos resultados do processo de monitoramento, com relação às não conformidades apontadas, pode ser visualizada na Figura 13.

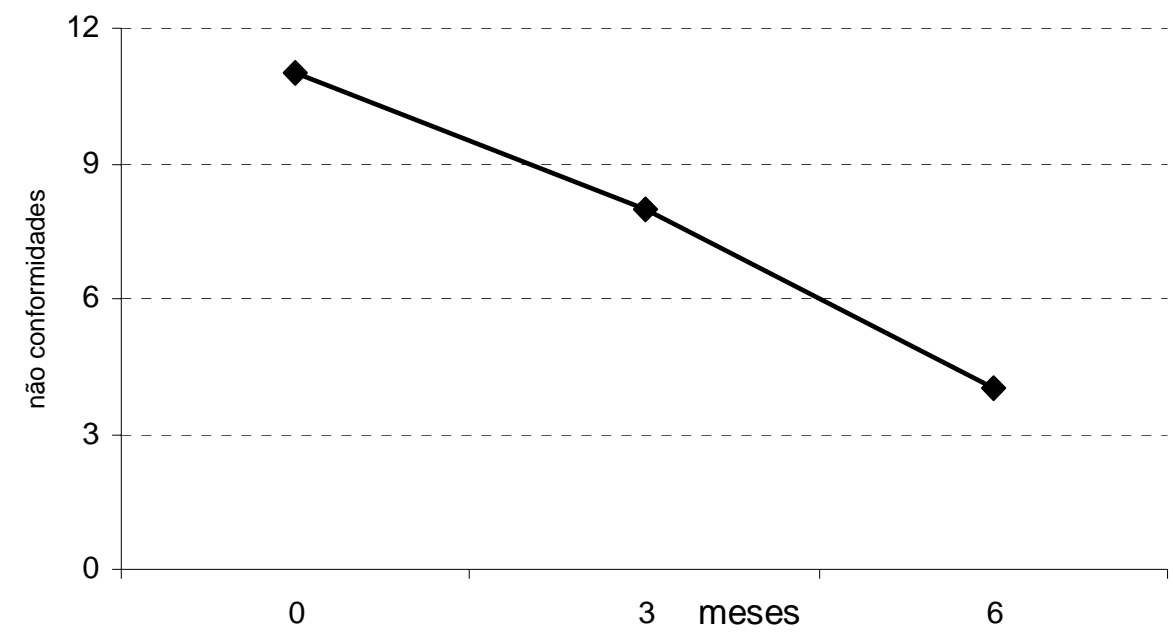

Figura 13 - Perfil dos resultados das monitorações 
Outro fator observado nos resultados das auditorias está relacionado aos itens estabelecidos no Sistema de Qualidade com o número de não conformidades encontradas.

A Tabela 12 apresenta a relação dos itens do Sistema de Qualidade com as não conformidades da primeira auditoria.

Tabela 12. Itens do sistema de qualidade afetados na primeira auditoria

\begin{tabular}{lc}
\hline \multicolumn{1}{c}{ Item do sistema de qualidade } & Não conformidade \\
\hline 1. Estrutura organizacional e responsabilidades & 1 \\
2. Departamento de garantia de qualidade & 1 \\
3. Localização e instalações do laboratório & 3 \\
4. Equipamentos e materiais & 2 \\
6. Amostra ou produto & 1 \\
7. Pessoal - manipulador das amostras & 1 \\
8. Pessoal - provador das amostras & 1 \\
10. Controle integrado de vetores e pragas urbanas & 1 \\
\hline
\end{tabular}

$\mathrm{Na}$ Tabela 13, são demonstrados os itens referentes ao Sistema de Qualidade que foram afetados na segunda auditoria.

Tabela 13. Itens do sistema de qualidade afetados na segunda auditoria

\begin{tabular}{ll}
\hline \multicolumn{1}{c}{ Item do sistema de qualidade } & Não conformidade \\
\hline 1. Estrutura organizacional e responsabilidades & 2 \\
4. Equipamentos e materiais & 1 \\
5. Procedimento Operacional Padrão & 1 \\
6. Amostra ou produto & 2 \\
7. Pessoal - manipulador das amostras & 1 \\
12. Arquivos de documentos e registros & 1 \\
\hline
\end{tabular}


Na Tabela 14, são apresentados os itens referentes ao Sistema de Qualidade que foram contemplados na terceira auditoria.

Tabela 14. Itens do sistema de qualidade afetados na terceira auditoria

\begin{tabular}{lc}
\hline \multicolumn{1}{c}{ Item do sistema de qualidade } & Não conformidade \\
\hline 1. Estrutura Organizacional e Responsabilidades & 1 \\
7. Pessoal - manipulador das amostras & 1 \\
9. Higiene e sanitização & 1 \\
10. Controle integrado de vetores e pragas urbanas & 1 \\
\hline
\end{tabular}

Ao analisar os dados apresentados dos itens do Sistema de Qualidade, que foram afetados na monitoração, verificou-se que, na primeira auditoria as ocorrências de não conformidades estavam relacionadas principalmente aos aspectos referentes às instalações e controle dos equipamentos do laboratório, em função do processo de implementação do sistema ter ocorrido após a estruturação das instalações e equipamentos.

Um dos motivos é que nas etapas de elaboração do projeto de construção, aquisição e disponibilização dos equipamentos, não foram levados em consideração os aspectos inerentes ao Sistema de Qualidade. Ao passo que, na segunda monitoração, os itens do Sistema de Qualidade abordados, se apresentaram relacionados às atividades operacionais e aos cumprimentos dos procedimentos, envolvendo principalmente o aspecto pessoal. Como ação corretiva, requerem tomadas de ações mais objetivas, promovendo a manutenção do comprometimento e motivação dos colaboradores da organização através de reciclagem dos treinamentos e cursos de aperfeiçoamento.

E finalmente na terceira monitoração, as ocorrências de não conformidades apresentaram-se mais distribuídas entre as atividades, não se caracterizando em um aspecto específico. 
Geralmente as propostas de ações corretivas são pontuais e individualizadas, que podem ser corrigidas de imediato ou que requerem curto prazo para aplicação, em função da sua simplicidade.

A relação dos itens do Sistema de Qualidade implementado, e as não conformidades apontadas estão ilustradas na Figura 14.

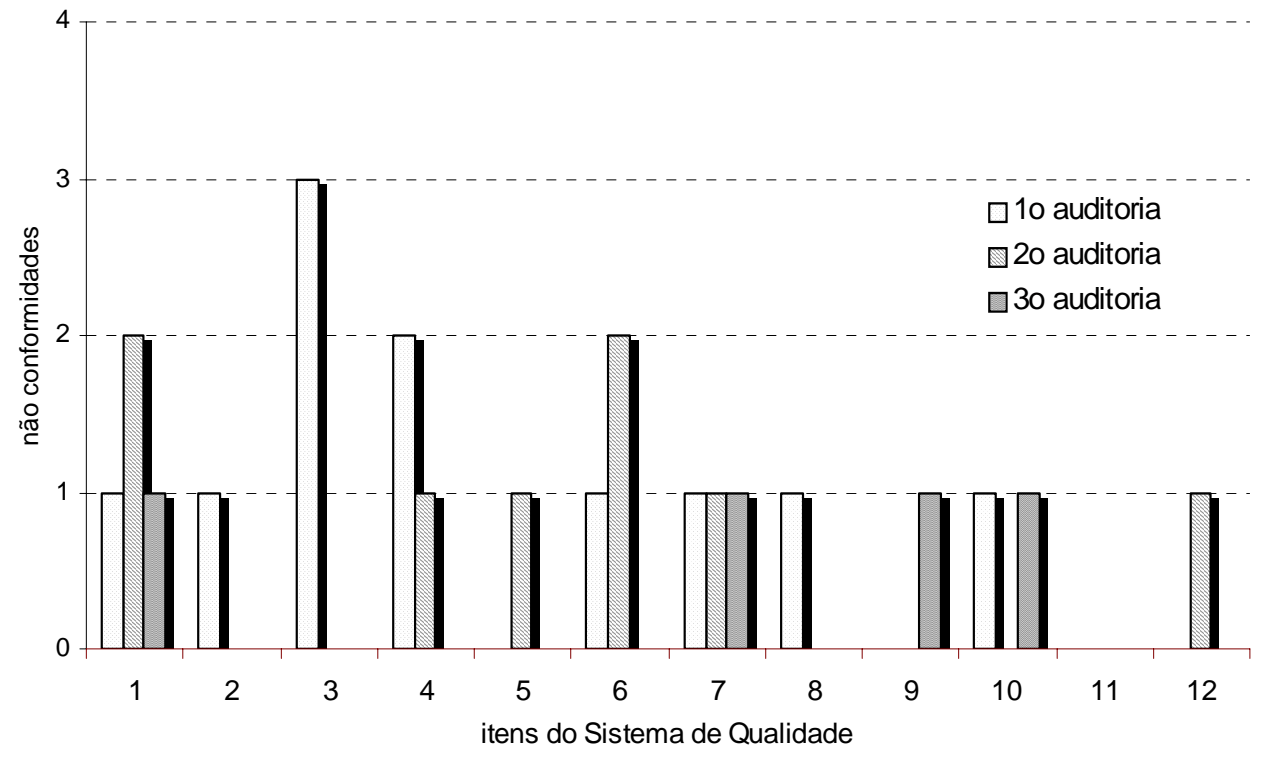

Figura 14 - Relação das não conformidades com os itens do sistema

Em função da sistemática que envolveu todo o processo de implementação do sistema e durante a avaliação, houve a necessidade da participação e do envolvimento dos colaboradores ao realizarem a elaboração dos procedimentos, desenvolverem o estudo para identificarem as causas das não conformidades e aplicarem as propostas de ações corretivas, dentre outras atividades. 
Esta movimentação estimulou mudanças no comportamento dos colaboradores do laboratório, e promoveu a habilidade de desenvolverem trabalhos em equipe, e buscarem sempre a melhoria do sistema. 


\section{CONCLUSÃO}

A implementação do Sistema de Qualidade no laboratório de análise sensorial da indústria de alimentos, baseado nos princípios das Boas Práticas de Laboratório (BPL) e Boas Práticas de Fabricação (BPF), demonstrou aplicabilidade.

A atividade desenvolvida na implementação do Sistema de Qualidade promoveu o processo de melhoria, através das não conformidades apontadas nas auditorias e do reflexo das ações corretivas tomadas.

Apesar da implementação do sistema ter se desenvolvido bem, até o presente momento, é necessário que ocorram atualizações periódicas do sistema implementado, para acompanhar o momento real das atividades envolvidas no escopo.

A limitação do trabalho foi a falta de tempo hábil para realizar o processo de implementação do Sistema de Qualidade em outros laboratórios de análise sensorial.

Este trabalho apresenta condições para o desenvolvimento de pesquisas com relação à análise de viabilidade econômica da implementação e a validação do sistema específico para as atividades do laboratório de análise sensorial. 
Anexo 1 - Lista de verificação para o processo de monitoramento

Itens de verificação

1. ESTRUTURA ORGANIZACIONAL

Apresenta organograma funcional do laboratório sensorial, com aprovação da alta direção da organização

Apresenta descrição de cargos, pré-requisitos e responsabilidade para cada função estabelecida

Apresenta documento de programação de treinamento e registro dos treinamentos realizados

Existe a função do coordenador do Sistema de Qualidade

O coordenador do Sistema de Qualidade está representado no organograma da empresa

2. GARANTIA DE QUALIDADE

O coordenador do departamento de garantia de qualidade tem formação, treinamento e experiência em Sistema de Qualidade, com comprovação documentada

Existe a equipe de auditores qualificada e treinada, há comprovação

Existe programação de treinamento e registros dos treinamentos realizados, para os membros do departamento de garantia da qualidade

As atividades exercidas no laboratório estão documentadas conforme padrão estabelecido, de forma instrutiva 
Anexo 1 - Lista de verificação para o processo de monitoramento

3. INSTALAÇÕES

A localização do laboratório está em área isenta de odores indesejáveis, fumaça, pó, poeira e outros contaminantes

As paredes são de cor clara e de fácil limpeza

O piso é constituído de material impermeável, lavável e antiderrapante

O piso apresenta ralos providos de sifão

As portas e janelas são de superfície lisa, de fácil limpeza e ajustadas aos batentes

Existe proteção contra insetos e roedores, são providos de telas ou outro sistema

Os ângulos entre as paredes e o piso são abaulados para facilitar a limpeza

O teto é constituído de material que impeça o acúmulo de sujeira As cabines de degustação garantem a individualidade do provador

Providas de iluminação branca e colorida Apresentam conforto ergonômico e térmico para os provadores Os equipamentos de ventilação artificial são providos de filtro As cabines estão dispostas de forma que não haja contato com a área de preparação

Existe sistema de comunicação luminosa do provador para o preparador da amostra

$\mathrm{Na}$ área que antecede às cabines de degustação, existe lavatório e acessórios a disposição dos provadores

Apresenta lavatório na área de manipulação, dotado de sabonete anti-séptico e acessórios para secar as mãos 
Anexo 1 - Lista de verificação para o processo de monitoramento 4. EQUIPAMENTOS E MATERIAIS

Os equipamentos estão dispostos de forma a permitir fácil acesso para operação e higienização Existem registros que comprovem a realização da manutenção preventiva dos equipamentos Existem documentos e registros que comprovem a calibração dos equipamentos, quando pertinente Os utensílios são de material atóxico, que não transmitem odor e sabor

Os utensílios são constituídos de superfície lisa e isenta de rugosidade ou outras imperfeições

5. PROCEDIMENTO OPERACIONAL PADRÃO (POP)

Existem procedimentos que descrevem como conduzir os ensaios do laboratório

Nos procedimentos verificados, constam as assinaturas de aprovação

Estão redigidos em estrutura padronizada

Contemplam dos itens estabelecidos para o cabeçalho e corpo do documento

O procedimento utilizado corresponde à revisão atualizada Há evidências de treinamento dos colaboradores para os procedimentos descritos 
Anexo 1 - Lista de verificação para o processo de monitoramento

6. AMOSTRA

As amostras apresentam identificação, data de recebimento, prazo de validade e condições de armazenamento

Estão armazenadas em condições especiais, conforme recomendado

Existem procedimentos que estabelecem as condições para o preparo das amostras

Apresenta sistemática para registrar as oscilações que possam ocorrer nas amostras e interferir no resultado do teste

7. MANIPULADORES

Existe programação de capacitação dos manipuladores e registros dos treinamentos realizados

Apresentam asseio de higiene pessoal, usando roupa protetora (jaleco branco), sapatos fechados e touca protetora

Os manipuladores mantêm as unhas curtas e limpas e não utilizam nenhum tipo de adorno como relógio, esmalte, batom e outros

Evitam praticar atos não sanitários que possa contaminar o alimento, como espirrar, fumar, tossir, coçar a cabeça, e outros Lavam as mãos antes da manipulação de alimentos, após qualquer interrupção e depois do uso de sanitários.

Existe cartaz de orientação aos manipuladores sobre a correta lavagem das mãos

Ausência de afecções cutâneas, infecções respiratórias e oculares

Existe programação de exames médicos e laboratoriais periódicos

Existe registro que comprove a realização dos exames 
Anexo 1- Lista de verificação para o processo de monitoramento

8. PROVADORES

Existe comprovação da seleção dos provadores, quando necessária equipe selecionada

Existe programação de treinamento dos provadores e registros dos treinamentos realizados

Os provadores têm conhecimento dos procedimentos da degustação e do objetivo da análise.

Existe sistemática para registrar as alterações percebidas no provador, que possam influenciar nos resultados do teste

9. HIGIENE E SANITIZAÇÃO

Existe Procedimento Operacional Padrão para a atividade de higiene e sanitização

O colaborador da operação de higiene e sanitização é treinado para exercer a atividade

Os produtos de higienização são registrados no Ministério da Saúde

Os produtos apresentam fichas técnicas e dados de segurança fornecidos pelo fabricante

Produtos de higienização estão identificados e guardados em local apropriado

Apresenta sistema de coleta seletiva para os lixos

As lixeiras são identificadas, providas de tampa pedal, revestidas com saco plástico resistente

Existe sistemática para comprovação do controle de qualidade da água através de registros de análises

Apresenta sistemática para a atividade de limpeza do reservatório de água 
Anexo 1 - Lista de verificação para o processo de monitoramento

10. CONTROLE INTEGRADO DE VETORES E PRAGAS

Existe sistemática para impedir ações de vetores e pragas

Contratam serviços de empresas controladoras de vetores e

pragas que são licenciadas por autoridade sanitária

Apresenta comprovação da aplicação de desinfestantes com

registros no Ministério da Saúde

Existe documento que certifica o trabalho da empresa contratada, com assinatura do técnico responsável

\section{ARQUIVOS DE DOCUMENTOS E REGISTROS}

Os arquivos são estruturados para o armazenar e garantir a integridade dos documentos e registros

O material retido nos arquivos é indexado de forma ordenada

Existe sistemática para o tempo de retenção dos documentos

Apresenta facilidade e prontidão para recuperação dos documentos arquivados

12. GARANTIA DA QUALIDADE

Existe programação de monitoramento e verificação

Existe equipe de auditores definida, com treinamento $\mathrm{e}$ capacitação registrada e documentada

Os registros de não conformidades do processo da auditoria apresentam em estrutura padronizada

Os registros de não conformidades estão preenchidos de acordo com a sistemática estabelecida

Os relatórios do monitoramento e verificação estão arquivados, indexados e de fácil disposição

* Condições de: $C=$ Conforme, NC= Não Conforme, NA= Não Aplicável 


\section{REFERÊNCIAS BIBLIOGRÁFICAS}

AMERICAN SOCIETY FOR TESTING AND MATERIALS. Standard practice for establishing conditions for laboratory evaluation of foods and beverages - ASTM E 480 - 84. Philadelphia, 1984. 5p.

AMBROZEWICZ, P.H.L. Qualidade na prática, conceitos e ferramentas. Brasília: SENAI, 2003. 118p.

ANDRADE, P.H.S. O impacto do programa 5s na implantação e manutenção de sistemas da qualidade. Florianópolis, 2002.159p. Dissertação (Mestrado) Universidade Federal de Santa Catarina.

AGENCIA NACIONAL DE VIGILÂNCIA SANITÁRIA. Gerência Geral de Laboratórios de Saúde Pública. Procedimentos operacionais da REBLAS. Critérios para a habilitação de laboratórios segundo os princípios das Boas Práticas de Laboratório (BPL). Brasília: ANVISA, 2001. 36p.

ATHAYDE, A. Controle integrado de pragas assegura inocuidade dos alimentos. Engenharia de Alimentos, v.6, n.29, p.20-25, 2000.

BENOLIEL, M.J. Step-by-step implementation of a quality system in the laboratory. Tends in Analytical Chemistry, v.18, n.9, p.632-638, 1999. 
BARBÊDO, A.D.D.;TURRIONI, J.B.;QUETE, T.C. Sistemas de gestão da qualidade no setor de serviços: um estudo de aplicabilidade em bibliotecas de ensino superior de uma cidade mineira. Revista Pesquisa e Desenvolvimento Engenharia de Produção, v.12,n.1, p. 63-76, dez. 2003.

BARQUETE, T.C. Desenvolvimento de um modelo de garantia de qualidade para laboratório baseado no sistema APPCC. Viçosa, 2000. 101p. Dissertação (M.S.) - Universidade Federal de Viçosa.

BARRY, W.S. Fundamentos da gerência. Rio de Janeiro: Zahar, 1974. 213p.

BRASIL. Ministério da Agricultura e do Abastecimento de Produtos Agropecuários. Portaria $n^{0}$ 368, de 04 de setembro de 1997. Regulamento técnico sobre as condições higiênico-sanitárias e de boas práticas de elaboração para estabelecimentos elaboradores/ industrializadores de alimentos. Brasília, Diário Oficial da União, 04 set. 1997a.

BRASIL. Ministério da Saúde. Secretaria de Vigilância Sanitária. Portaria $n^{\circ}$ 1.428, de 26 de novembro de 1993. Regulamento técnico sobre inspeção sanitária, boas práticas de produção/ prestação de serviços e padrão de identidade e qualidade na área de alimentos. Brasília, Diário Oficial da União, 02 dez. 1993.

BRASIL. Ministério da Saúde. Secretaria de Vigilância Sanitária. Portaria $n^{\circ}$ 326, de 30 de julho de 1997. Regulamento técnico sobre as condições higiênico-sanitárias e de boas práticas de fabricação para indústrias de alimentos. Brasília, Diário Oficial da União, 01 ago. 1997b. 
BRASIL. Ministério da Saúde. Secretaria de Vigilância Sanitária. Portaria nº 09, de 16 de novembro de 2000. Norma técnica para empresas prestadoras de serviço em controle de vetores e pragas urbanas. Brasília, Diário Oficial da União, 16 nov. 2000.

BRASIL. Ministério da Saúde. Agência Nacional de Vigilância Sanitária. Resolução $n^{\circ} 275$, de 21 de outubro de 2002. Regulamento técnico de procedimentos operacionais padronizados aplicados aos estabelecimentos produtores/ industrializadores de alimentos e a lista de verificação das boas práticas de fabricação em estabelecimentos produtores/industrializadores de alimentos. Brasília, Diário Oficial da União, 23 out. 2002.

BRASIL. Ministério da Saúde. Agência Nacional de Vigilância Sanitária. Portaria $n^{\circ} 216$, de 15 de setembro 2004. Regulamento técnico de boas práticas para serviços de alimentação. Brasília, Diário Oficial da União, 16 set. 2004a.

BRASIL. Ministério da Saúde. Gabinete do Ministro. Portaria n 518, de 25 de março de 2004. Norma de qualidade da água para consumo humano. Brasília, Diário Oficial da União, 26 mar. 2004b.

CALEGARE, A.J.A. Como avaliar a implantação da qualidade total em organizações. Barueri: Inter Qual International Quallity Systems, 1999.

CAMPOS, V.F. Gerenciamento da rotina do trabalho do dia a dia. Belo Horizonte: INDG - Tecnologia e Serviço Ltda, 2004. 266p.

CROSBY, P.B. Qualidade sem lágrimas: a arte da gerência descomplicada. 3.ed. Rio de Janeiro: José Olympio, 1994. 236p. 
DEMING, W.E. Qualidade: a revolução da administração. Rio de Janeiro: Saraiva, 1990. 367p.

FARIA, E.V. Técnicas de análise sensorial. Campinas: ITAL 2002. 116p.

FEIGENBAUM, A.V. Controle da qualidade total: gestão de sistemas. São Paulo: Mcgraw Hill, 1994. 205p.

FOOD SAFETY AND INSPECTION SERVICE. Sanitation standard operating procedures. Washington, 2003. 59p.

GRAAF, de C.; CARDELLO, A.V.; KRAMER, F.M.; LESHER, L.L.; MEISELMAN, H.L.; SCHUTZ, H.G. A comparison between liking ratings obtained under laboratory and field conditions: the role of choice. Appetite, v.44, p.15-22, 2005.

GARVIN, G. Managing quality: the strategic and competitive edge. New York: Free Press, 1988. 319p.

GARNER, W.Y.; BARGEM.S.; USSARY, J.P. Normas de boas práticas de laboratório: aplicações de estudo de campo e laboratório. Camaçari: CEPED, 1996. 560p.

HAJDENWURCEL, J.R. A experiência da indústria de laticínios na implantação do sistema APPCC - estudo de caso. Indústria de Laticínios, v.40, p.24-31, jul./ago.2002.

HUTCHINS, G. ISO 9000: um guia completo par o registro, as diretrizes da auditoria e a certificação bem sucedida. São Paulo: Makron, 1994. 280p. 
INSTITUTO NACIONAL DE METROLOGIA. Critérios para o credenciamento de laboratórios de ensaio segundo os princípios das boas práticas de laboratório. Norma NIT - DICLA - 028. Brasília, 2003. 30p.

INTERNATIONAL ORGANIZATION FOR STANDARDIZATION. Sensory analysis - general guidance for the selection, training and monitoring of assessors. ISO 8586-1. Geneva, 1993. 15p.

INTERNATIONAL ORGANIZATION FOR STANDARDIZATION. Sensory analysis - general guidance for the design of test rooms. ISO 8589. Geneva, 1988. $9 p$.

ISHIKAWA, K. Guide to quality control. New York: QR, 1994. 225p.

KOTLER, P. Administração de marketing: análise planejamento, implementação e controle. São Paulo: Atlas, 1998. 724p.

KOZLOWSKA, K.; JERUSZKA, M.; MATUSZEWSKA, I.; ROSZKOWSKI, W.; BARYLKO-PIKIELNA, N.; BRZOZOWSKA, A. Hedonic tests in different locations as predictors of apple juice consumption at home in elderly and young subjects. Food Quality and Preference, v.14, p.653-661, 2003.

LAS CASAS, A.L. Qualidade total em serviços - conceitos, exercícios e casos práticos. São Paulo: Atlas, 1999. 206p.

LOPES, E.A. Controle preventivo da qualidade e segurança alimentar: boas práticas de fabricação e outros procedimentos correlatos. Campinas: FEA UNICAMP, 2001. 
MALMFORS, T.; MARCO, P. di; SAVOLAINEN, K. Good Evaluation Practice: a proposal of guidelines. Toxicology Letters, v.151, p.19-23, 2004.

MCEWAN, J.A. Comparison of sensory panels: a ring trial. Food Quality and Perference, v.10, p.161-171, 1999.

MARANHÃO, M. ISO série ISO 9000: manual de implantação. 2.ed. Rio de Janeiro: Qualitymark, 1994. 360p.

MEILGAARD, M.; CIVILLE, G.V.; CARR, B.T. Sensory evatuation techniques. 3.ed. Boca Raton: CRC Press, 1999. 387p.

MELLO, C.H.P.; da SILVA, C.E.S.; TURRIONI, J.B.; de SOUZA, L.G.M. Sistema de gestão da qualidade para operações de produtos e serviços: ISO 9001:2000. São Paulo: Atlas, 2002. 221p.

MIGUEL, P.A.C. Qualidade: enfoques e ferramentas. São Paulo: Artiliber, 2001. 263p.

NASCIMENTO, E.S. Importância da implantação de sistemas de garantia da qualidade em laboratórios analíticos. Revista Brasileira de Toxicologia, v.1 n.11, p.15-17, 1999.

ORGANIZATION FOR ECONOMIC CO-OPERATION AND DEVELOPMENT. Series on principles of good laboratory practices and compliance monitoring. Paris, 1998. 44p.

PALADINI, E.P. Gestão da qualidade: teoria e prática. São Paulo: Atlas, 2000. $330 p$. 
PALADINI, E.P. Qualidade total na prática: implantação e validação de sistemas de qualidade total. 2.ed. São Paulo: Atlas, 1997. 214p.

PRAZERES, P.M. Dicionário de termos da qualidade. São Paulo: Altas, 1996. $456 p$.

SCHMIDT, P. Integrating accreditation - good laboratory practice and good manufacturing practice in an industrial analytical laboratory. Accreditation Quality Assurance, v.1, n.4, p.129-132, 1999.

SERVIÇO NACIONAL DE APRENDIZAGEM INDUSTRIAL. Elementos de apoio para o sistema APPCC. 2.ed. Brasília, 2000. 361p.

SLACK, N.; CHAMBERS, S.; HARLAND, C.; HARRISON, A.; JOHNSTON, R. Administração da produção. São Paulo: Atlas, 2002. 747p. 